\title{
No strong evidence that social network index is associated with gray matter
}

\section{volume from a data-driven investigation}

Chujun Lin1*, Umit Keles1, J. Michael Tyszka1, Marcos Gallo1, Lynn Paulı, Ralph Adolphs1,2

1 Division of Humanities and Social Sciences, California Institute of Technology, CA, USA.

${ }_{2}$ Division of Biology and Biological Engineering, California Institute of Technology, CA, USA.

*Correspondence to: clin7@ caltech.edu 
Abstract: Recent studies in adult humans have reported correlations between individual differences in people's Social Network Index (SNI) and gray matter volume (GMV) across multiple regions of the brain. However, the cortical and subcortical loci identified are inconsistent across studies. These discrepancies might arise because different regions of interest were hypothesized and tested in different studies without controlling for multiple comparisons, and/or from insufficiently large sample sizes to fully protect against statistically unreliable findings. Here we took a data-driven approach in a pre-registered study to comprehensively investigate the relationship between SNI and GMV in every cortical and subcortical region, using three predictive modeling frameworks. We also included psychological predictors such as cognitive and emotional intelligence, personality, and mood. In a sample of healthy adults $(\mathrm{n}=$ 92), neither multivariate frameworks (e.g., ridge regression with cross-validation) nor univariate frameworks (e.g., univariate linear regression with cross-validation) showed a significant association between SNI and any GMV or psychological feature after multiple comparison corrections (all R-squared values $\leq 0.1$ ). These results emphasize the importance of large sample sizes and hypothesis-driven studies to derive statistically reliable conclusions, and suggest that future meta-analyses will be needed to more accurately estimate the true effect sizes in this field.

Keywords: social network index, gray matter volume, predictive modeling, cross-validation 


\section{1. Introduction}

2 It has been well-documented that neocortex volume is positively correlated with social group

3 size across multiple primate species (Dunbar, 1998; Dunbar \& Shultz, 2007), an intriguing

4 finding that has motivated a number of subsequent studies in humans (see below). It is important

5 to keep in mind that social group size is of course not the only factor in the evolution of large

6 brains: it is merely one variable amongst many interacting variables that determines fitness. For

7 instance, diet and other ecological variables are also associated with brain size (Barton, 1999).

8 Nonetheless, across the many variables that contribute to brain size (or to gray matter volume of

9 specific structures), social group size remains as one of the most robust when studies examine

10 this question across species (Dunbar \& Shultz, 2017).

11 While the correlation between brain volume and social group size is robust across species, it has

12 also been suggested that a similar association might obtain across individuals within a species:

13 some individuals are embedded in larger or smaller social groups, and one might expect this

14 variation in social behavior to be related to the brain. In particular, one might expect the variation

15 to be related to brain structures implicated in social cognition. A number of studies have

16 examined this within-species hypothesis in humans (Table 1) by correlating GMV of structures

17 such as amygdala with various social network metrics, in particular self-reports of the number of

18 people one has contacted within a given period, such as the social network index or SNI, a metric

19 we also used in the present study.

20 A study in macaques even suggests the causal hypothesis that social group size could cause

21 changes in brain size (Sallet et al., 2011): macaques randomly assigned to live in larger groups

22 showed increased GMV in certain brain structures thought to underlie social cognition. Whether

23 on the timescale of evolution or of the life of an individual, the above varied findings raise the 
1 hypothesis that social network metrics in humans might be correlated with GMV in specific

2 brain structures.

3 However, characterizing social networks in humans is fundamentally different from quantifying

4 social group size in other primates due to the greater complexity and variability of human social

5 relationships (Dunbar, 1998). Previous studies attempting to test the within-species hypothesis in

6 humans (Table 1) have employed various metrics of social networks, such as the number of

7 people one had seen or talked to at least once every two weeks (Bickart, Hollenbeck, Barrett, \&

8 Dickerson, 2012; Bickart, Wright, Dautoff, Dickerson, \& Barrett, 2011; Bickart et al., 2011), the

9 number of people one had contacted over the last 12 months, 30 days, or 7 days (Kwak, Joo,

10 Youm, \& Chey, 2018; Lewis, Rezaie, Brown, Roberts, \& Dunbar, 2011; Noonan, Mars, Sallet,

11 Dunbar, \& Fellows, 2018; Powell Joanne, Lewis Penelope A., Roberts Neil, García-Fiñana

12 Marta, \& Dunbar R. I. M., 2012), or the number of friends one had on social media (Kanai,

13 Bahrami, Roylance, \& Rees, 2012). While all those metrics can fluctuate over months, weeks,

14 and even days for an individual, GMV of brain structures are relatively stable over time in

15 healthy adults. This makes at least some metrics of social networks in humans, such as the SNI,

16 prima facie implausible candidates for being correlated with variability in structural brain

17 measures, raising some caution about how to interpret any putative findings.

18 Indeed, previous studies in humans investigating the relationship between social network metrics

19 and GMV have produced inconsistent results (Table 1). For instance, while some studies showed

20 that bilateral amygdala volume was positively correlated with SNI (Bickart et al., 2011), others

21 failed to replicate these relationships (Spagna et al., 2018). In addition, the different regions of

22 interest hypothesized, and different methods for correcting for multiple comparisons used in past 
1 research might also contribute to the discrepant findings (Kanai et al., 2012; Lewis et al., 2011;

2 Noonan et al., 2018).

3 Here, we took a purely data-driven approach to examine the relationship between SNI and GMV,

4 with the aim of uncovering any relationships with specific brain regions. We did not hypothesize

5 SNI to correlate with GMV of any specific brain region, and instead comprehensively tested the

6 effect of every cortical and subcortical volume to see if an agnostic approach would discover (or

7 reproduce) any candidates. We examined these relationships using three different predictive

8 modeling frameworks, which capitalized on the strengths of both multivariate analyses and

9 univariate analyses, explored the prediction performance with or without feature selection, and

10 implemented cross-validation to increase the generalizability of our results. To handle multiple

11 comparisons, all effects within a framework was corrected for false discovery rate (FDR). Since

12 previous studies have also reported that various psychological measures such as personality and

13 perceived stress were linked to individual differences in social networks (Asendorpf \& Wilpers,

14 1998; Nabi, Prestin, \& So, 2013), we also included a list of psychological measures in our

15 frameworks. All hypotheses and measures were preregistered and can be accessed at

16 https://osf.io/mpjkz/?view_only=7fd32ce53d434f4b8dbd0339579a8efa.

\section{Table 1}

18 Summary of previous studies in humans on the correlations between social network metrics and

19 GMV of cortical and subcortical structures of the brain. Abbreviations: L left, R right, ITS

20 inferior temporal sulcus, SFG superior frontal gyrus, ACC anterior cingulate cortex, mPFC

21 medial prefrontal cortex, TPJ temporoparietal junction, STS superior temporal sulcus, OFC

22 orbitofrontal cortex, AIC anterior insular cortex. 


\begin{tabular}{|c|c|c|c|c|c|c|}
\hline Literature & $\begin{array}{l}\text { Hypothesized } \\
\text { Regions (ROIs) }\end{array}$ & $\begin{array}{l}\text { Social } \\
\text { Network } \\
\text { Metrics }\end{array}$ & $\begin{array}{l}\text { Sample } \\
\text { Size }\end{array}$ & $\begin{array}{l}\text { Age } \\
\text { Range }\end{array}$ & $\begin{array}{l}\text { Correction for Multiple } \\
\text { Comparisons }\end{array}$ & Significant Regions \\
\hline $\begin{array}{l}\text { Bickart et } \\
\text { al., } 2011\end{array}$ & $\begin{array}{l}\text { 1) amygdala } \\
\text { 2) hippocampus } \\
\text { 3) exploratory } \\
\text { analysis of all } \\
\text { other subcortical } \\
\text { regions } \\
\text { 4) exploratory } \\
\text { analysis of all } \\
\text { cortical thickness }\end{array}$ & $\begin{array}{l}2 \text { subscales } \\
\text { of SNI: the } \\
\text { number of } \\
\text { people in } \\
\text { social } \\
\text { network, } \\
\text { the number } \\
\text { of embedded } \\
\text { networks }\end{array}$ & $\mathrm{N}=58$ & $19-83$ & $\begin{array}{l}\text { For } 1 \text { ) and 2): linear } \\
\text { regressions, uncorrected } \\
\text { For 3): linear regressions, } \\
\text { Bonferroni correction for } \\
\text { testing multiple regions, } \\
\text { but not for multiple SNIs } \\
\text { For 4): general linear } \\
\text { regressions, uncorrected }\end{array}$ & $\begin{array}{l}\mathrm{L} \text { amygdala } \\
\mathrm{R} \text { amygdala } \\
\text { If uncorrected for } \\
\text { multiple comparison } \\
(p<0.01) \text {, also: } \\
\text { R subgenual ACC } \\
\text { L caudal SFG } \\
\text { L caudal ITS }\end{array}$ \\
\hline $\begin{array}{l}\text { Lewis et } \\
\text { al., } 2011\end{array}$ & $\begin{array}{l}\text { 1) } \mathrm{mPFC} \\
\text { 2) TPJ } \\
\text { 3) STS } \\
\text { 4) frontal pole }\end{array}$ & $\begin{array}{l}\text { Dunbar's } \\
\text { number: the } \\
\text { number of } \\
\text { people } \\
\text { contacted in } \\
\text { previous } 30 \\
\text { days }\end{array}$ & $\mathrm{N}=45$ & $18-50$ & $\begin{array}{l}\mathrm{p}<0.001 \text { uncorrected } \\
\text { with an extent threshold } \\
\text { of }>5 \text { voxels within ROIs } \\
* \text { survived small volume } \\
\text { correction at } \mathrm{p}=0.05 \\
\text { with } 8 \mathrm{~mm} \text { radius spheres }\end{array}$ & $\begin{array}{l}\text { *Ventromedial } \\
\text { frontal gyrus } \\
\text { Medial orbitofrontal } \\
\text { gyrus }\end{array}$ \\
\hline $\begin{array}{l}\text { Kanai et } \\
\text { al., } 2012\end{array}$ & $\begin{array}{l}\text { 1) amygdala } \\
\text { 2) posterior STS } \\
\text { 3) TPJ } \\
\text { 4) mPFC } \\
\text { 5) precuneus } \\
\text { 6) medial } \\
\text { temporal lobe }\end{array}$ & $\begin{array}{l}\text { Online } \\
\text { social } \\
\text { network } \\
\text { size: the } \\
\text { number of } \\
\text { Facebook } \\
\text { friends }\end{array}$ & $\begin{array}{l}\text { Sample } 1 \\
\mathrm{~N}=125 \\
\text { Sample } 2 \\
\mathrm{~N}=40\end{array}$ & $\begin{array}{l}\text { Sample 1 } \\
23 \pm 4 \\
\text { Sample 2 } \\
22 \pm 3\end{array}$ & $\begin{array}{l}\text { Sample } 1 \\
\mathrm{p}<0.05 \text { family-wise } \\
\text { error corrected for the } \\
\text { whole-brain volume } \\
\text { *only survived correction } \\
\text { for small volumes of } 10 \\
\text { mm spheres around ROIs } \\
\text { Sample } 2 \\
\mathrm{p}<0.05 \text { uncorrected for } \\
\text { testing multiple loci } \\
\text { identified in Sample } 1\end{array}$ & $\begin{array}{l}\mathrm{R} \text { posterior STS } \\
\mathrm{R} \text { entorhinal } \\
\mathrm{L} \text { middle temporal } \\
\text { gyrus } \\
* \mathrm{~L} \text { amygdala } \\
* \mathrm{R} \text { amygdala }\end{array}$ \\
\hline $\begin{array}{l}\text { Bickart et } \\
\text { al., } 2012\end{array}$ & $\begin{array}{l}\text { 1) amygdala, } \\
\text { controlling for } \\
\text { network } \\
\text { connectivity }\end{array}$ & $\begin{array}{l}\text { All three } \\
\text { subscales of } \\
\text { SNI }\end{array}$ & $\mathrm{N}=29$ & $19-32$ & $\begin{array}{l}\text { Linear regressions, } \\
\text { uncorrected }\end{array}$ & Amygdala \\
\hline $\begin{array}{l}\text { Powell, et } \\
\text { al., } 2012\end{array}$ & $\begin{array}{l}\text { 1) orbital PFC } \\
\text { 2) dorsal PFC }\end{array}$ & $\begin{array}{l}\text { The number } \\
\text { of people } \\
\text { contacted in } \\
\text { previous } 7 \\
\text { days }\end{array}$ & $\mathrm{N}=40$ & $18-47$ & Path analysis, uncorrected & Orbital PFC \\
\hline $\begin{array}{l}\text { Von Der } \\
\text { Heide et } \\
\text { al., } 2014\end{array}$ & $\begin{array}{l}\text { 1) amygdala } \\
\text { 2) R subgenual } \\
\text { ACC } \\
\text { 3) L posterior } \\
\text { ITS } \\
\text { 4) L posterior } \\
\text { SFG } \\
\text { 5) posterior STS } \\
\text { 6) middle } \\
\text { temporal gyrus } \\
\text { 7) entorhinal } \\
\text { 8) OFC }\end{array}$ & $\begin{array}{l}3 \text { measures: } \\
\text { the number } \\
\text { of Facebook } \\
\text { friends, } \\
\text { Dunbar's } \\
\text { number, } \\
\text { Norbeck } \\
\text { Social } \\
\text { Support }\end{array}$ & $\begin{array}{l}\mathrm{N}=40 \\
\text { females }\end{array}$ & $12-30$ & $\begin{array}{l}\mathrm{p}<0.05 \text { family-wise } \\
\text { error corrected for small } \\
\text { volumes of } 10 \mathrm{~mm} \text { radius } \\
\text { spheres around the ROIs; } \\
\text { uncorrected for testing } \\
\text { multiple measures }\end{array}$ & $\begin{array}{l}\text { L amygdala, } \\
\text { R amygdala, } \\
\text { L posterior ITS } \\
\text { L posterior SFG } \\
\text { L entorhinal } \\
\text { R entorhinal } \\
\text { L OFC } \\
\text { R OFC }\end{array}$ \\
\hline $\begin{array}{l}\text { Noonan et } \\
\text { al., } 2018\end{array}$ & 1) $\mathrm{ACC}$ & $\begin{array}{l}2 \text { measures: } \\
\text { the number } \\
\text { of people } \\
\text { contacted in }\end{array}$ & $\mathrm{N}=18$ & $52 \pm 15$ & $\begin{array}{l}\text { Whole brain approach } \\
\text { only reporting regions } \\
\text { that bilaterally survive } \\
(\mathrm{p}<0.0001) \text { with an }\end{array}$ & $\begin{array}{l}\text { Subcallosal parts of } \\
\text { vmPFC } \\
\text { Anterior temporal } \\
\text { cortex }\end{array}$ \\
\hline
\end{tabular}




\begin{tabular}{|c|c|c|c|c|c|c|}
\hline & & $\begin{array}{l}\text { previous } 7 \\
\text { days, } \\
\text { the number } \\
\text { of people } \\
\text { contacted in } \\
\text { previous } 30 \\
\text { days }\end{array}$ & & & $\begin{array}{l}\text { extent threshold of }>40 \\
\text { voxels } \\
\text { ROI approach } \\
p<0.05 \text { family-wise } \\
\text { error corrected for small } \\
\text { volumes of all voxels in } \\
\text { the ROI }\end{array}$ & $\begin{array}{l}\text { The border of } \\
\text { posterior cingulate } \\
\text { cortex and precuneus }\end{array}$ \\
\hline $\begin{array}{l}\text { Spagna et } \\
\text { al., } \\
2018\end{array}$ & $\begin{array}{l}\text { 1) AIC } \\
\text { 2) amygdala } \\
\text { 3) exploratory } \\
\text { analysis of all } \\
\text { other cortical } \\
\text { thickness }\end{array}$ & $\begin{array}{l}\text { A composite } \\
\text { measure of } \\
\text { all three } \\
\text { subscales of } \\
\text { SNI }\end{array}$ & $\begin{array}{l}\text { Sample } 1 \\
N=50 \\
\text { Sample } 2 \\
N=100\end{array}$ & $\begin{array}{l}\text { Sample } 1 \\
19-37 \\
\text { Sample } 2 \\
18-29\end{array}$ & $\begin{array}{l}\text { For } 1 \text { ) and } 2 \text { ): } \mathrm{p}<0.05 \\
\text { with contiguous-voxel } \\
\text { extent thresholds } \\
\text { estimated using } \\
\text { AlphaSim } \\
\text { For } 3 \text { ): } \mathrm{p}<0.05 \text { family- } \\
\text { wise error corrected for } \\
\text { the whole-brain volume }\end{array}$ & $\begin{array}{l}\text { L AIC in Sample } 1 \\
\text { R AIC in Sample } 2 \\
\text { and when both } \\
\text { samples were } \\
\text { combined }\end{array}$ \\
\hline $\begin{array}{l}\text { Kwak et } \\
\text { al., } 2018\end{array}$ & $\begin{array}{l}\text { 1) amygdala } \\
\text { 2) OFC } \\
\text { 3) dorsal mPFC } \\
\text { 4) TPJ } \\
\text { 5) precuneus }\end{array}$ & $\begin{array}{l}\text { The number } \\
\text { of people } \\
\text { discussed } \\
\text { things with } \\
\text { in the last } 12 \\
\text { months }\end{array}$ & $\mathrm{N}=68$ & $59-84$ & $\begin{array}{l}\mathrm{p}<0.05 \text { family-wise } \\
\text { error corrected with a } \\
\text { cluster defining threshold } \\
\text { of } \mathrm{p}<0.001 \text { estimated by } \\
\text { the Gaussian random } \\
\text { field }\end{array}$ & $\begin{array}{l}\text { R OFC } \\
\text { dorsal mPFC }\end{array}$ \\
\hline
\end{tabular}

\section{2. Material and methods}

\subsection{Participants}

$4 \quad$ Ninety-two healthy participants (41 females, Age $(\mathrm{M}=29.64, \mathrm{SD}=6.30$, ranged from 18 to 47))

5 were recruited from the Los Angeles metropolitan area by the Caltech Conte Center for Social

6 Decision-Making (P50 MH094258). All participants were fluent in English, had normal or

7 corrected-to-normal vision and hearing, had Full Scale Intelligence Quotient greater than or

8 equal to 90, had no first degree relative with schizophrenia or autism spectrum disorder, and had

9 no history of developmental, psychiatric, or neurological disease. All participants provided

10 written informed consent approved by the Institutional Review Board of the California Institute

11 of Technology.

\section{$12 \quad 2.2$ Magnetic Resonance Imaging}

13 All MRI data was acquired using a 3T whole-body system (Magnetom TIM Trio, Siemens

14 Medical Solutions, Malvern, PA) with a 32 channel receive head array at the Caltech Brain

15 Imaging Center. Structural imaging data was acquired by the Imaging Core of the Caltech Conte 
1 Center for Social and Decision Neuroscience as part of a larger, multi-group consortium and analyzed retrospectively for this project. Structural images were acquired with one of two

3 imaging protocols, corresponding to the first and second phases of the Caltech Conte Center (61

4 participants from Phase 1 and 31 participants from Phase 2). The Phase 1 protocol included two

5 independent MP-RAGE acquisitions with TR/TE/TI $=1500 / 2.9 / 800 \mathrm{~ms}$, flip angle $=10^{\circ}, 1 \mathrm{~mm}$

6 isotropic voxels, 176 slab partitions, no in-plane GRAPPA, for a total imaging time of 12

7 minutes 52 seconds. The Phase 2 protocol included a single multi-echo MP-RAGE (MEMP-

8 RAGE) acquisition with TR/TE/TI $=2530 / 1.6$ to $7.2 / 1100 \mathrm{~ms}$, flip angle $=7^{\circ}, 0.9 \mathrm{~mm}$ isotropic

9 voxels, 208 slab partitions, in-plane GRAPPA R = 2, for a total imaging time of 6 minutes 3

10 seconds. Both protocols generated T1-weighted structural images with comparable tissue contrast,

11 SNR (following image or echo averaging) and voxel dimensions.

\section{$12 \quad 2.3$ Estimation of cortical and subcortical volumes}

13 Individual structural images were segmented and the cortical gray matter ribbon parcellated

14 using the recon-all pipeline from Freesurfer v6.0.0 (Fischl, 2012). The pipeline initially

15 registered and averaged the two separate T1-weighted images from the Phase 1 protocol prior to

16 subsequent processing. Images from Phase 1 and Phase 2 protocols were processed

17 independently and all images were resampled isotropically to $1 \mathrm{~mm}$ voxels prior to RF bias field

18 correction and tissue segmentation. One hundred and forty-eight cortical gray matter parcel

19 volumes (74 parcellations per hemisphere) corresponding to the Destrieux 2009 atlas (Destrieux,

20 Fischl, Dale, \& Halgren, 2010), seventeen subcortical region volumes, and estimated total

21 intracranial volumes were compiled from the Freesurfer output for subsequent analysis in $R$. All

22 cortical and subcortical volumes were normalized with respect to estimated total intracranial

23 volume. 


\subsection{Social network index}

2 The social network metric used in the present study is a subscale of the social network index, or

3 SNI (Cohen, Doyle, Skoner, Rabin, \& Gwaltney, 1997). This metric is a self-report questionnaire

4 that quantifies the number of people participants saw or talked to at least once every two weeks

5 in 12 different social relationships (e.g., spouse, children, relative, friend, neighbor, workmate).

6 Participants from Phase 1 and Phase 2 did not differ in mean SNI $(t=0.93, p=0.355$; two-

7 sample two-sided t-test). In addition to the SNI, we also asked participants to provide the modes

8 of communication (e.g., face-to-face conversation, text, voice/video chat, social media) and types

9 of support (e.g., emotional support, physical assistance, advice/information, companionship)

10 used in those social relationships. Those variables were measured for the purpose of exploring

11 whether SNI might be also associated with individual differences in modes of communication

12 and types of support, as preregistered (see Appendix A).

\section{$13 \quad 2.5$ Psychological measures}

14 The cognitive ability of participants was measured with the Wechsler Abbreviated Scales of

15 Intelligence-II (Wechsler, 2011), deriving two scores, verbal comprehension $(\mathrm{M}=109.20, \mathrm{SD}=$

16 10.02) and perceptual reasoning $(\mathrm{M}=104.80, \mathrm{SD}=10.86)$. The emotional intelligence $(\mathrm{EI})$ of

17 participants was measured with the Mayer-Salovey-Caruso Emotional Intelligence Test (Mayer,

18 Salovey, \& Caruso, 2002), deriving two sub-scores, experiential EI $(\mathrm{M}=103.60, \mathrm{SD}=14.48)$

19 and strategic EI $(\mathrm{M}=99.49, \mathrm{SD}=10.54)$. The empathy level of participants was measured with

20 the Empathy Quotient (Baron-Cohen \& Wheelwright, 2004) [M=50.84, SD = 12.05]. The

21 personality of participants was measured with the Sixteen Personality Factor Questionnaire

22 (Cattell, Eber, \& Tatsuoka, 1970; Russell, Karol, \& Institute for Personality and Ability Testing,

23 2002), deriving five global scores, extraversion $(M=5.62, S D=1.85)$, independence $(M=6.14$, 
$1 \mathrm{SD}=1.67)$, tough-mindedness $(\mathrm{M}=4.35, \mathrm{SD}=1.60)$, self-control $(\mathrm{M}=4.35, \mathrm{SD}=1.38)$, and

2 anxiety $(\mathrm{M}=5.65, \mathrm{SD}=1.85)$. The affect of participants was measured with the Positive and

3 Negative Affect Schedule (Watson, Clark, \& Carey, 1988), deriving two scores, positive affect

$4 \quad(\mathrm{M}=31.68, \mathrm{SD}=8.43)$ and negative affect $(\mathrm{M}=12.53, \mathrm{SD}=4.03)$. The stress level of

5 participants was measured with the Perceived Stress Scale (Cohen, Kamarck, \& Mermelstein,

6 1983) $[\mathrm{M}=12.36, \mathrm{SD}=6.52]$. The depression severity of participants was measured with the

7 Beck Depression Inventory-II (Beck, Steer, \& Brown, 1996) $[\mathrm{M}=5.08, \mathrm{SD}=5.60]$. The trait

8 anxiety of participants was measured with the State-Trait Anxiety Inventory (Speilberger,

9 Gorusch, Lushene, Vagg, \& Jacobs, 1983) $[\mathrm{M}=34.96, \mathrm{SD}=9.31]$.

\subsection{Predictive modeling framework}

11 To comprehensively understand the relationship between SNI and GMV, we carried out three

12 independent analyses using three different predictive modeling frameworks (Figure 1).

13 Framework 1 follows our pre-registered analysis plan and performed multivariate analysis (ridge

14 regression) with cross-validation and feature selection. As recommended by recent research

15 (Finn et al., 2015), we used univariate Pearson's correlation between each feature and SNI as a

16 criterion for feature selection. Specifically, we had an outer cross-validation loop that randomly

17 split the data into training (80\%) and test (20\%) sets for 2000 iterations; in each outer loop

18 iteration, the univariate Pearson's correlation between each feature and SNI was assessed using

19 the training data, and features that showed significant correlations with $\mathrm{SNI}(p<0.05)$ were

20 selected to construct a ridge regression model to predict SNI; the prediction accuracy of the

21 model was then assessed using the test data. The hyperparameter (regularization penalty) of ridge

22 regression was tuned using a nested cross-validation loop: the training data from the outer cross-

23 validation loop were further randomly split into inner-training (80\%) and inner-test (20\%) for 20 
1 iterations, and the optimal hyperparameter value was selected among 20 values in the interval of

$2[1,10000]$ across the 20 iterations.

3 To address the concern that the feature selection procedure might have omitted some features

4 that did have associations with SNI, Framework 2 performed ridge regression with cross-

5 validation without feature selection: the same procedures as in Framework 1 were used to

6 construct the outer cross-validation loop and to tune the hyperparameter of ridge regression,

7 except that the ridge regression model was fitted with all features in each iteration instead of

8 selected features. To address the concern that the weights produced by multivariate models such

9 as ridge regression could be misleading in the presence of correlated noise (Haufe et al., 2014;

10 Kriegeskorte \& Douglas, 2019), Framework 3 performed univariate linear regressions between

11 every feature and SNI with cross-validation; cross-validation was constructed following the same

12 procedures as in the first two frameworks for the outer cross-validation loop.

A Ridge regression with feature selection
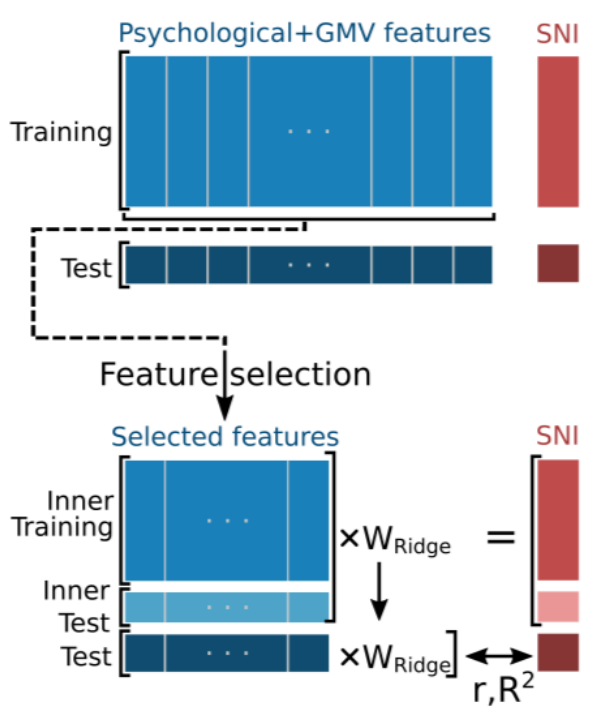

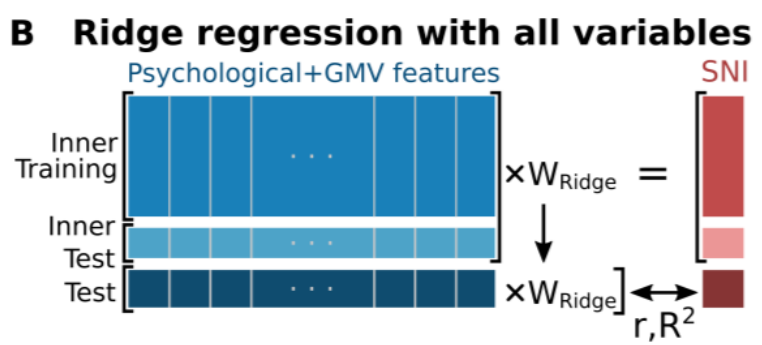

C Univariate linear regression

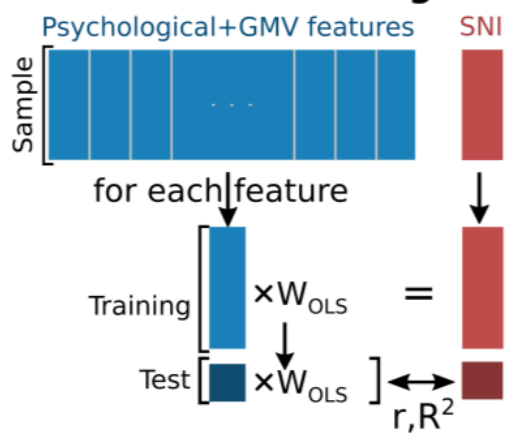

14 Fig. 1. Illustration of three predictive modeling frameworks. 
1 (A) Framework 1 performed ridge regression with cross-validation using selected features.

2 Features were selected within the cross-validation loop based on univariate correlations. The

3 hyperparameter of ridge regression was tuned using a nested cross-validation loop. (B)

4 Framework 2 performed ridge regression with cross-validation using all features. (C) Framework

53 performed univariate ordinary least-squares linear regression between each feature and SNI

6 within the cross-validation loop.

7 The prediction accuracy of each framework was assessed with two measures, Pearson's $r$ and

8 prediction $R^{2}$. Pearson's $r$ assessed the correlation between observed and predicted values of SNI

9 in the test data. Prediction $R^{2}$ measured the improvement of predicting SNI with our frameworks

10 over the observed mean of SNI in the test data. The final reported prediction accuracy for each

11 framework was averaged over the 2000 (outer loop) cross-validation splits. The p-values of

12 prediction accuracies and model coefficients were calculated from permutations, where the null

13 distributions were generated by randomly permuting the SNI labels across the sample for 10,000

14 iterations and in each iteration repeating all the analysis steps of a predictive framework. We

15 handled multiple comparisons by correcting for false discovery rate $(q<0.05)$, which was

16 applied when multiple features were tested for associations with SNI independently (i.e.,

17 univariate correlations in Framework 3) as well as when they were tested jointly (i.e., model

18 coefficients in Frameworks 1 and 2). We handled the only binary feature, gender, by both

19 removing the feature (which generated the results we reported here) and stratification (i.e., the

20 training and test sets in cross-validation had approximately equal number of males and females);

21 results from stratification corroborated those reported in the present paper. All analysis codes can

22 be accessed at the Open Science Framework

23 https://osf.io/zumwt/?view_only=4f11ca10ed5947c1be1ecdea57cfdff3. 


\section{3. Results}

2 As preregistered, we first analyzed whether individual differences in SNI could be predicted by

3 demographic characteristics and psychological measures alone. An exploratory factor analysis

4 showed that a six-dimensional structure underlies the common variance of these eighteen

5 psychological/demographic features (negative affect, cognitive control, extraversion, emotional

6 intelligence, education, age and gender, see Appendix B). Analyses across all three frameworks

7 consistently indicated that these eighteen psychological/demographic features alone did not

8 predict SNI (see Appendix C).

9 Next, we inspected whether cortical and subcortical GMV together with psychological/

10 demographic features could predict individual differences in SNI. Analyses from Framework 3

11 showed that the effect size of every feature was weak, and none of the features alone predicted

12 SNI after correcting for multiple comparisons (Table 2; see Appendix D for results of every

13 feature). While univariate analyses generated model coefficients that were straightforward to

14 interpret, they left open the question of whether multiple features combined might predict SNI.

15 Analyses from Framework 1 and 2 showed that features in their entirety did not predict SNI

16 either (Fig. 2).

17 Table 2

18 Results from univariate analyses of Framework 3. Model coefficients and prediction accuracies

19 (with SDs, and p-values corrected for FDR) of the top ten features with the largest positive and

20 negative effect sizes. Abbreviations: L left, R right, G gyrus/gyri, S sulcus/sulci, coeff coefficient.

\begin{tabular}{|l|c|c|c|c|c|c|c|c|c|}
\hline Features & coeff & $\begin{array}{c}\text { coeff- } \\
\text { SD }\end{array}$ & $\begin{array}{c}\text { coeff- } \\
\mathbf{p}\end{array}$ & $\mathbf{r}$ & $\mathrm{r}$-SD & $\mathbf{r}-\mathrm{p}$ & $\mathbf{R 2}$ & $\begin{array}{c}\text { R2- } \\
\text { SD }\end{array}$ & $\begin{array}{c}\text { R2- } \\
\mathrm{p}\end{array}$ \\
\hline 16PF_Extraversion & $\mathbf{0 . 3 6}$ & 0.04 & 0.13 & $\mathbf{0 . 3 5}$ & 0.18 & 0.78 & $\mathbf{0 . 1 0}$ & 0.13 & 0.77 \\
\hline 16PF_Independence & $\mathbf{0 . 3 1}$ & 0.05 & 0.44 & $\mathbf{0 . 2 9}$ & 0.23 & 0.78 & $\mathbf{0 . 0 6}$ & 0.16 & 0.77 \\
\hline L-Accumbens-area & $\mathbf{0 . 2 3}$ & 0.05 & 0.89 & $\mathbf{0 . 2 3}$ & 0.20 & 0.78 & $\mathbf{0 . 0 3}$ & 0.09 & 0.77 \\
\hline
\end{tabular}


bioRxiv preprint first posted online Dec. 27, 2019; doi: http://dx.doi.org/10.1101/2019.12.19.883173. The copyright holder for this preprint (which was not peer-reviewed) is the author/funder, who has granted bioRxiv a license to display the preprint in perpetuity.

It is made available under a CC-BY-NC-ND 4.0 International license.

\begin{tabular}{|l|c|c|c|c|c|c|c|c|c|}
\hline Empathy Quotient & $\mathbf{0 . 2 2}$ & 0.05 & 0.89 & $\mathbf{0 . 2 0}$ & 0.22 & 0.78 & $\mathbf{0 . 0 2}$ & 0.10 & 0.77 \\
\hline PANAS-Positive & $\mathbf{0 . 2 0}$ & 0.04 & 0.89 & $\mathbf{0 . 1 9}$ & 0.18 & 0.78 & $\mathbf{0 . 0 2}$ & 0.08 & 0.77 \\
\hline L-Middle-temporal-G & $\mathbf{0 . 1 9}$ & 0.05 & 0.89 & $\mathbf{0 . 1 7}$ & 0.19 & 0.78 & $\mathbf{0 . 0 1}$ & 0.08 & 0.77 \\
\hline L-Planum-temporale-superior-temporal-G & $\mathbf{0 . 1 8}$ & 0.06 & 0.89 & $\mathbf{0 . 1 7}$ & 0.25 & 0.78 & $\mathbf{0 . 0 0}$ & 0.10 & 0.77 \\
\hline R-Caudate & $\mathbf{0 . 1 7}$ & 0.06 & 0.89 & $\mathbf{0 . 1 7}$ & 0.23 & 0.78 & $\mathbf{0 . 0 0}$ & 0.09 & 0.77 \\
\hline L-Anterior-circular-S-insula & $\mathbf{0 . 1 7}$ & 0.06 & 0.89 & $\mathbf{0 . 1 2}$ & 0.25 & 0.78 & $\mathbf{- 0 . 0 2}$ & 0.09 & 0.77 \\
\hline L-Caudate & $\mathbf{0 . 1 5}$ & 0.06 & 0.89 & $\mathbf{0 . 1 5}$ & 0.23 & 0.78 & $\mathbf{- 0 . 0 1}$ & 0.08 & 0.77 \\
\hline L-Calcarine-S & $\mathbf{- 0 . 1 8}$ & 0.05 & 0.89 & $\mathbf{0 . 1 8}$ & 0.20 & 0.78 & $\mathbf{0 . 0 1}$ & 0.08 & 0.77 \\
\hline L-Inferior-circular-S-insula & $\mathbf{- 0 . 1 8}$ & 0.04 & 0.89 & $\mathbf{0 . 1 8}$ & 0.17 & 0.78 & $\mathbf{0 . 0 2}$ & 0.06 & 0.77 \\
\hline R-Cuneus & $\mathbf{- 0 . 1 9}$ & 0.05 & 0.89 & $\mathbf{0 . 1 9}$ & 0.19 & 0.78 & $\mathbf{0 . 0 2}$ & 0.08 & 0.77 \\
\hline L-Anterior-transverse-collateral-S & $\mathbf{- 0 . 2 1}$ & 0.06 & 0.89 & $\mathbf{0 . 2 0}$ & 0.23 & 0.78 & $\mathbf{0 . 0 1}$ & 0.11 & 0.77 \\
\hline Perceived Stress & $\mathbf{- 0 . 2 2}$ & 0.04 & 0.89 & $\mathbf{0 . 2 2}$ & 0.18 & 0.78 & $\mathbf{0 . 0 3}$ & 0.08 & 0.77 \\
\hline L-Temporal-pole & $\mathbf{- 0 . 2 4}$ & 0.05 & 0.89 & $\mathbf{0 . 2 4}$ & 0.19 & 0.78 & $\mathbf{0 . 0 4}$ & 0.10 & 0.77 \\
\hline STAI-Trait & $\mathbf{- 0 . 2 6}$ & 0.04 & 0.79 & $\mathbf{0 . 2 5}$ & 0.18 & 0.78 & $\mathbf{0 . 0 5}$ & 0.10 & 0.77 \\
\hline L-Paracentral-lobule\&S & $\mathbf{- 0 . 2 9}$ & 0.05 & 0.44 & $\mathbf{0 . 2 9}$ & 0.19 & 0.78 & $\mathbf{0 . 0 7}$ & 0.12 & 0.77 \\
\hline R-Lingual-medial-occipitotemporal-G & $\mathbf{- 0 . 3 0}$ & 0.04 & 0.44 & $\mathbf{0 . 3 1}$ & 0.17 & 0.78 & $\mathbf{0 . 0 8}$ & 0.10 & 0.77 \\
\hline L-Inferior-occipital-G\&S & $\mathbf{- . 3 5}$ & 0.04 & 0.13 & $\mathbf{0 . 3 4}$ & 0.18 & 0.78 & $\mathbf{0 . 1 0}$ & 0.13 & 0.77 \\
\hline
\end{tabular}
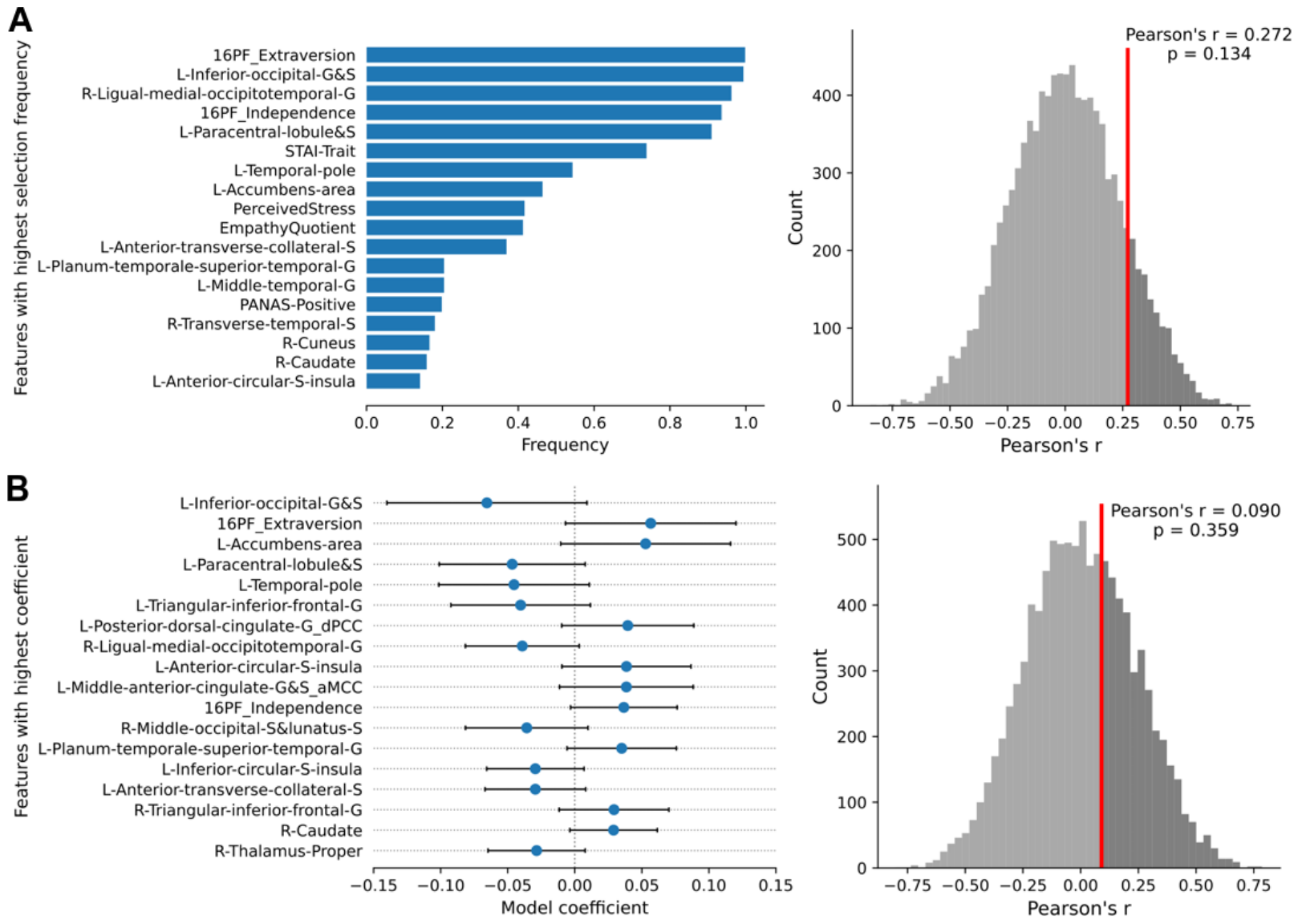

4 Fig. 2. Predicting SNI with all GMV and psychological/demographic features. 
1 (A) Results from analyses of Framework 1. The selection frequency (blue bars) of the top (most

2 frequently selected) eighteen features over the 2000 iterations of the outer cross-validation loop

3 (left) and the mean prediction accuracy (red vertical line, assessed with Pearson's r) averaged

4 over the 2000 outer cross-validation iterations compared to the null distribution generated with

5 permutation (right). The mean prediction accuracy assessed with prediction $R^{2}=0.060, \mathrm{p}=$

6 0.136. (B) Results from analyses of Framework 2. Model coefficients (blue dots) and standard

7 deviations (black bars) of the top eighteen features (left) and the mean prediction accuracy (red

8 vertical line, assessed with Pearson's r) averaged over the 2000 outer cross-validation iterations

9 compared to the null distribution generated with permutation (right). The mean prediction

10 accuracy assessed with prediction $R^{2}=-0.023, \mathrm{p}=0.404$.

11 While our study used a predictive framework (using cross-validation), we also recognize the

12 value of descriptive effect sizes in providing results that could be used to formulate hypotheses

13 to be tested in future studies. To that end, we also show, for every cortical and subcortical region

14 over the brain, the univariate effect size of the correlation between SNI and GMV estimated

15 using all data (Figure 3, Appendix E). 

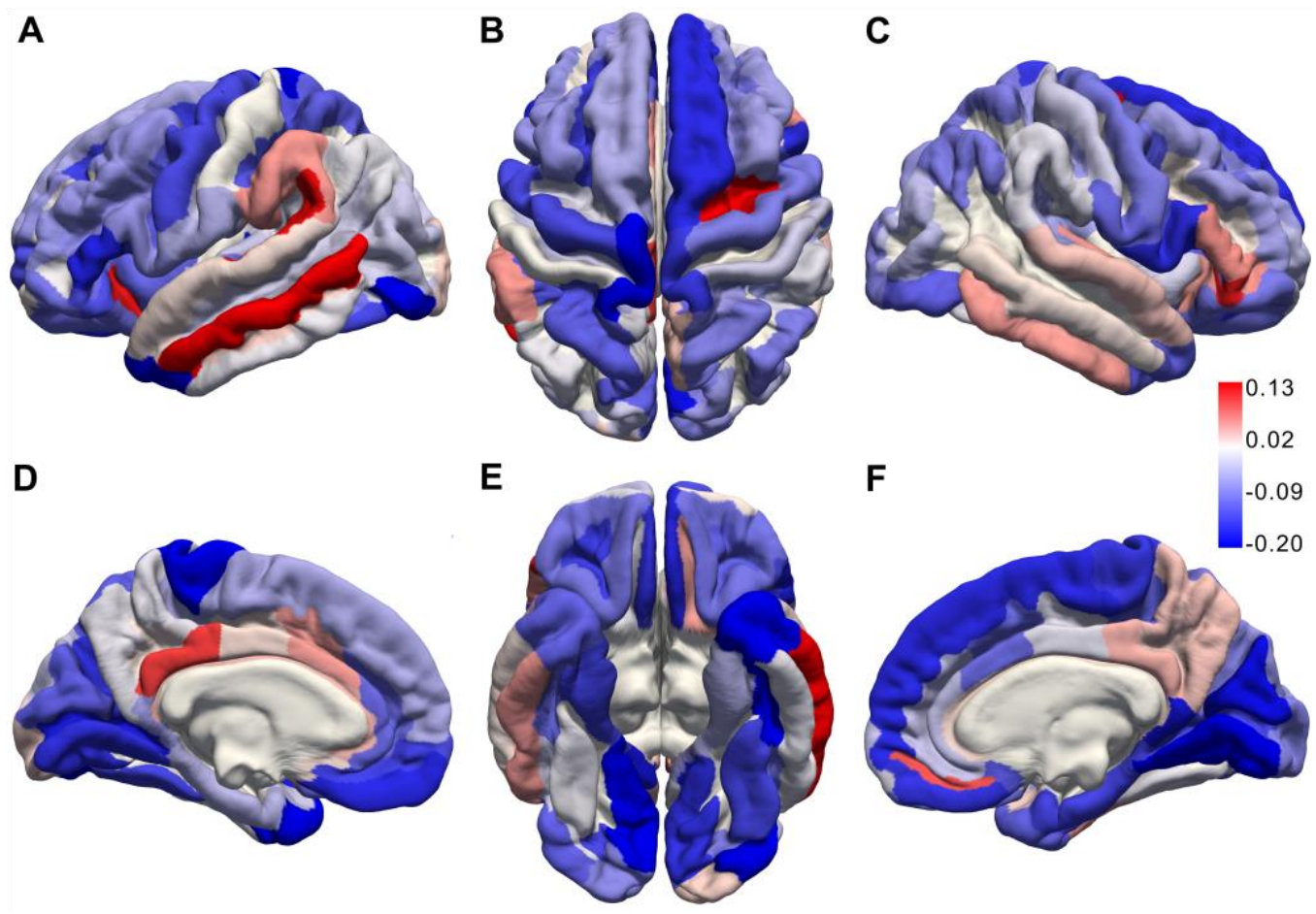

2 Fig. 3. Descriptive effect sizes between SNI and every cortical GMV.

3 The descriptive effect size of the univariate associations between all cortical regions and SNI are

4 shown to provide background for future studies that could test hypotheses based on these results.

5 Four renderings of the univariate Pearson correlations (uncorrected) between individual cortical

6 regions and SNI are projected on the pial surface for (A) the lateral view of the left hemisphere,

7 (B) the superior view of both hemispheres, (C) the lateral view of the right hemisphere, (D) the

8 medial view of the left hemisphere, (E) the inferior view of both hemispheres, and (F) the medial

9 view of the right hemisphere. These effect sizes provide recommendations for the sample sizes

10 required to test associations between specific cortical regions and SNI, shown in Appendix E.

\section{4. Discussion}

12 Following our preregistration, we applied a data-driven approach to comprehensively examine

13 the relationship between SNI and demographic, psychological, cortical and subcortical GMV 
1 features, using three different predictive modeling frameworks (Fig. 1). In our sample of healthy

2 adult humans, no evidence was found that any feature was significantly associated with SNI after

3 multiple comparison corrections (Fig. 2 and Table 2). It is important to note that whether a given

4 effect will be detected as significant or not is of course highly dependent on the sample size (i.e.,

5 the larger the sample size, the easier it is to detect a given effect size); similarly, estimated effect

6 sizes and their statistical significance will vary depending on the analysis frameworks (e.g.,

7 methods for model construction and multiple comparison corrections). Our study used a

8 comparatively large sample, tested three different predictive modeling frameworks, and included

9 pre-registration to verify the degrees of freedom in our analyses and to facilitate sharing of data

10 and codes. Regardless of statistical significance, we note that the estimated effect size of most

11 features, in particular 159 of the 165 cortical and subcortical GMV features, were very weak,

12 even when assessed with the simplest univariate correlation method (absolute values less than

13 0.20; see Fig. 3 and Appendix E). These findings do not demonstrate that there is no association

14 between GMV and SNI, but they do urge caution in interpreting prior reports of such

15 associations. We suggest that additional studies are needed on this topic, and that a future meta-

16 analysis based on all studies will be required to obtain a more accurate estimate of the true effect

17 sizes on this topic.

18 Three features reported in previous studies (Table 1; Asendorpf \& Wilpers, 1998) to have a

19 significant positive association with social network metrics-extraversion, left middle temporal

20 gyrus GMV, and left anterior insula GMV - and one feature reported in previous studies (Nabi,

21 Prestin, \& So, 2013) to have a significant negative as sociation with social network metrics-

22 perceived stress - indeed showed relatively larger effect sizes in expected directions among the

23 features in our sample (Table 2). However, those effect sizes were still very weak and were not 
1 significant in our study after multiple comparison corrections. The left temporal pole GMV has

2 also been reported to positively correlate with social network metrics (Table 1); though this

3 region showed a relatively larger effect size among our features (Table 2), it was in the opposite

4 direction from what has been reported previously (negative). Previously unreported regions in

5 the left occipital cortex also showed a relatively larger negative effect among the features. We do

6 not have an explanation for these negative effects and suggest that they may well be statistically

7 unreliable effects that turned up by chance given that we sampled all brain regions - indeed,

8 these negative effects were not significant after multiple comparison corrections. Nonetheless,

9 the specific GMV regions discussed in this section should serve as predictors in future

10 hypothesis-driven studies that could focus on one or several of these features.

11 We previously noted the reliable positive correlation between neocortex volume and social group

12 size found across species (Dunbar, 1998; Dunbar \& Shultz, 2007), and that this finding might

13 suggest the possibility that such a relationship would also exist across individuals within a single

14 species such as humans. However, any reliable relationship between social network metrics for a

15 specific individual and GMV is less plausible once we consider that social network metrics such

16 as SNI in individual humans is quite changeable, fluctuating as people move to new locations,

17 get a new job, or encounter other common transitions in their lives. Our failure to replicate

18 previously reported effects of GMV fit with this picture, and raise the possibility that many prior

19 findings might be false positives. Measures other than the SNI that could obtain more temporally

20 stable metrics related to social network size would seem better suited for investigating

21 associations with GMV. Alternatively, more dynamic measures of brain function, rather than

22 structure, would seem better suited for exploring associations with SNI. We would expect that

23 functional measures (or possibly others, such as from diffusion MRI) might well yield 
1 associations with SNI (Bickart, Hollenbeck, Barrett, \& Dickerson, 2012; Dziura \& Thompson,

2 2014; Hampton, Unger, Von Der Heide, \& Olson, 2016; Pillemer, Holtzer, \& Blumen, 2017).

3 The non-significant effects of many previously reported regions that we found in the present

4 study might be related to several limitations of our study, and of course do not demonstrate that

5 there is no effect. First, compared to the seminal study that reported a correlation between

6 amygdala volume and SNI (Bickart et al., 2011), our sample has a narrower age range, which

7 might result in less variability in amygdala volume and therefore lower power to detect an

8 association between amygdala volume and SNI. Second, all cortical and subcortical GMV used

9 in the present study were measured based on automated segmentations from FreeSurfer without

10 any manual correction (although we did carry out manual checks on a subset of the segmentation

11 results to verify their quality). This procedure has been shown to be no less accurate than manual

12 labeling (Bickart et al., 2011; Fischl et al., 2002), yet potential errors in segmentation might have

13 also reduced power to find a relationship between SNI and GMV.

14 We conclude with three recommendations for future research. First, studies attempting to test the

15 relationship between social network metrics and structural brain measures in humans should first

16 ensure that their respective sets of measures are approximately matched in terms of temporal

17 stability (e.g., using structural MRI predictors for temporally stable network measures, but

18 functional MRI predictors for metrics such as the SNI). Second, given concerns about false

19 positives when testing for associations between multiple regions and social network metrics,

20 future studies should try to preregister their hypotheses - and in particular, methods of correcting

21 for multiple comparisons - before conducting the analyses (Nosek, Ebersole, DeHaven, \&

22 Mellor, 2018). Such preregistered studies, if focused on specific neuroanatomical regions, should

23 include sample sizes sufficiently large to detect the hypothesized associations (Appendix E). As 
1 well, it is essential for studies to share all data and codes (e.g., through OSF) so that future meta-

2 analyses can capitalize on all accumulated findings. Third, future studies should focus on

3 understanding the mechanisms that might explain any association between social network

4 metrics and GMV of some regions in the brain. For example, some studies have suggested that

5 mentalizing might mediate such associations (Powell, Lewis, Roberts, García-Fiñana, \& Dunbar,

6 2012). This hypothesis could be tested with a more formal structural equation model, namely,

7 that GMV in brain regions thought to subserve mentalizing causes individual differences in

8 actual mentalizing ability in real life, which in turn has a causal effect on how many people an

9 individual associates with in social networks. Future studies employing longitudinal designs (e.g.,

10 repeatedly measuring social network metrics and GMV over years), mediation analyses, and

11 meta-analyses would shed new light on the mechanisms underlying the relationship between

12 social network metrics and structural brain measures. 


\section{Appendices}

3 Appendix A. Correlations between SNI, modes of communication, and types of support.

4 As preregistered, we explored the relationship between SNI and modes of communication and

5 types of support in the 12 social relationships. We collected these measures in two independent

6 samples of participants (an in-lab sample with 57 participants and an online-sample with 101

7 participants), reporting findings in both samples as replications. Besides the Social Network

8 Index (from which we derived all three scores: the number of people in network, network

9 diversity, and the number of embedded networks), participants were asked whether they used

10 any of the seven modes of communication (face-to-face conversation, text, voice/video chat,

11 email, social media, gaming, touch) in each social relationship, and furthermore whether they

12 received or provided any of the five types of support (emotional support, physical/material

13 assistance, advice/information, appraisal, companionship) in each social relationship. A

14 summary score for each mode and each type of support was derived by averaging the responses

15 across all social relationships. Numbers indicate the average correlation across the two samples.

16 Numbers were colored only if the correlations were significant in both samples. 
bioRxiv preprint first posted online Dec. 27, 2019; doi: http://dx.doi.org/10.1101/2019.12.19.883173. The copyright holder for this preprint (which was not peer-reviewed) is the author/funder, who has granted bioRxiv a license to display the preprint in perpetuity. It is made available under a CC-BY-NC-ND 4.0 International license.

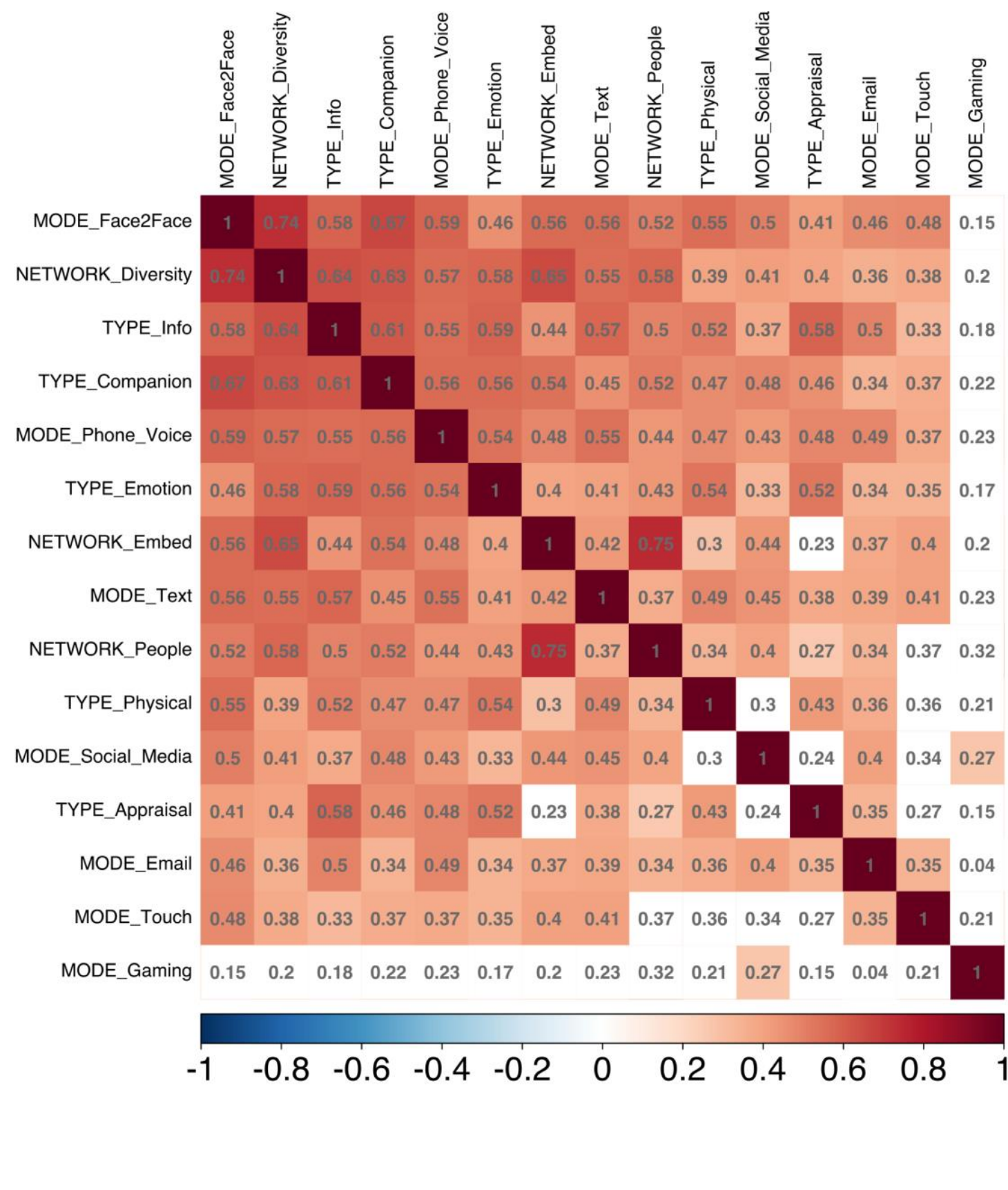




\section{Appendix B. Exploratory factor analysis on demographic characteristics and psychological}

2 measures.

3 Cattell's scree test and Kaiser's rule both indicated that a six-factor structure underlies the

4 common variance in the data. Therefore, we applied exploratory factor analysis to extract six

5 factors using the minimal residual method. The solutions were rotated with oblimin for

6 interpretability. Each column plotted the strength of the factor loadings (x-axis, absolute value)

7 across all demographic characteristics and psychological measures. The color of the bar

8 indicated the sign of the loading (red for positive and blue for negative; more saturated for higher

9 absolute values).

10
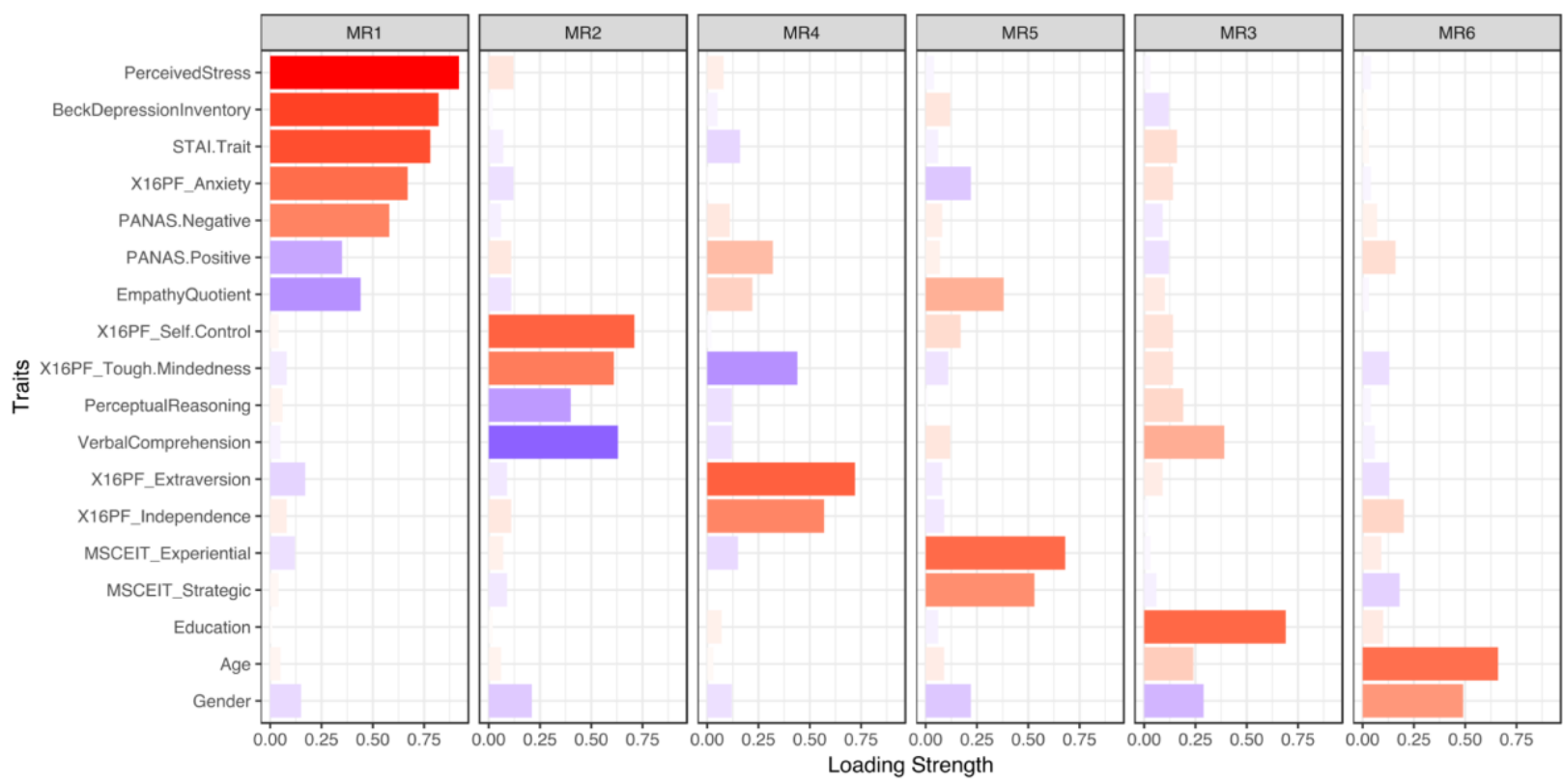
bioRxiv preprint first posted online Dec. 27, 2019; doi: http://dx.doi.org/10.1101/2019.12.19.883173. The copyright holder for this preprint (which was not peer-reviewed) is the author/funder, who has granted bioRxiv a license to display the preprint in perpetuity.

It is made available under a CC-BY-NC-ND 4.0 International license.

\section{Appendix C. Predicting SNI with demographic and psychological features alone.}

2 (A) The selection frequency of each feature (left) and the model prediction accuracy compared

3 with the null distribution (right) obtained from Framework 1. The model accuracy assessed with

4 prediction $R^{2}=0.085, p=0.072$. (B) The model coefficients and standard deviations (left) and

5 the model prediction accuracy compared with the null distribution (right) obtained from

6 Framework 2. The model accuracy assessed with prediction $R^{2}=0.054, p=0.185$. (C) The

7 model coefficients and accuracies (assessed with both Pearson's $r$ and prediction $R^{2}$ ) with SDs

8 and p-values corrected for FDR obtained from Framework 3.

A
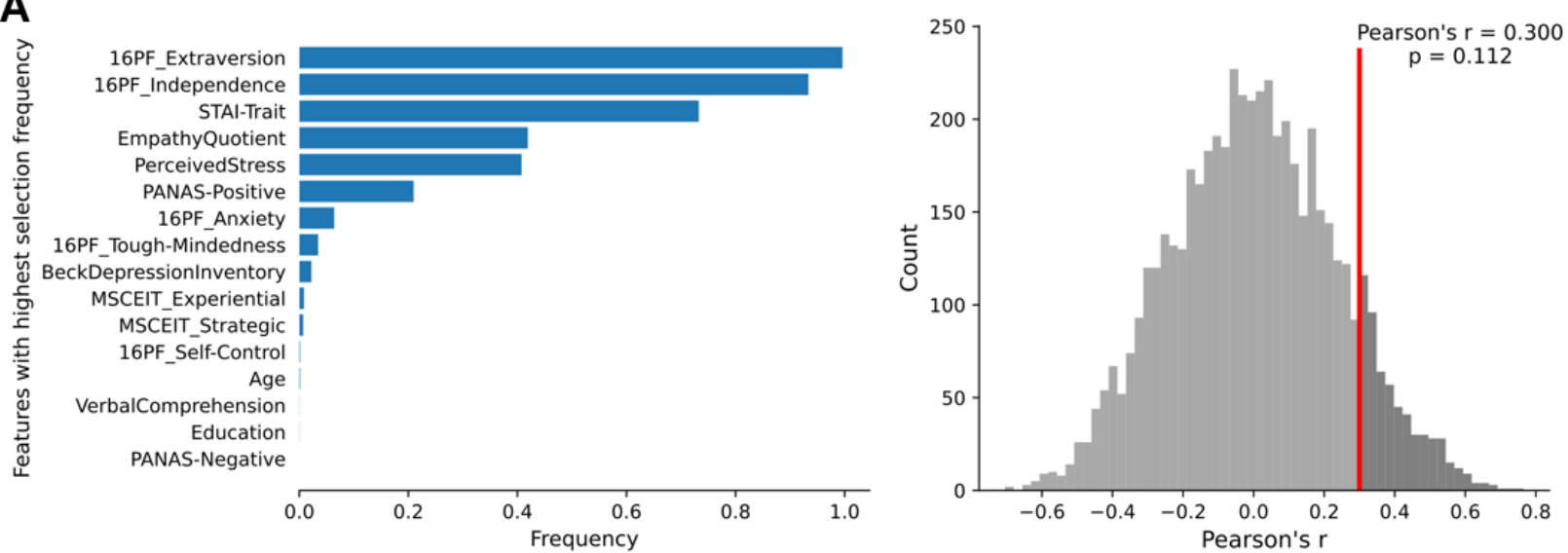

10
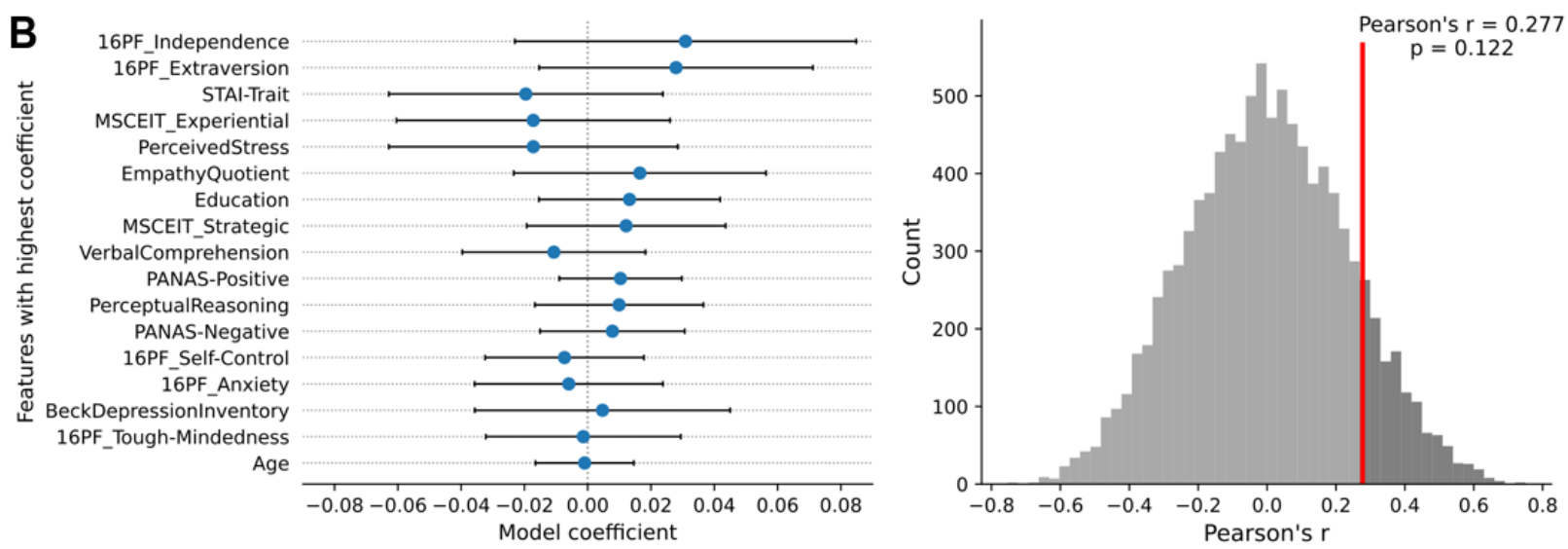
C

\begin{tabular}{|l|c|c|c|c|c|c|c|c|c|}
\hline Features & Coeff & $\begin{array}{c}\text { Coeff- } \\
\text { SD }\end{array}$ & $\begin{array}{c}\text { Coeff- } \\
\text { p- } \\
\text { correct }\end{array}$ & $\begin{array}{c}\text { Accuracy- } \\
\mathbf{r}\end{array}$ & r-SD & $\begin{array}{c}\text { r-p- } \\
\text { correct }\end{array}$ & $\begin{array}{c}\text { Accuracy- } \\
\text { R2 }\end{array}$ & $\begin{array}{c}\text { R2- } \\
\text { SD }\end{array}$ & $\begin{array}{c}\text { R2-p- } \\
\text { correct }\end{array}$ \\
\hline 16PF: Extraversion & $\mathbf{0 . 3 6}$ & 0.04 & 0.03 & $\mathbf{0 . 3 5}$ & 0.18 & 0.60 & $\mathbf{0 . 1 0}$ & 0.13 & 0.28 \\
\hline 16PF: Independence & $\mathbf{0 . 3 1}$ & 0.05 & 0.06 & $\mathbf{0 . 2 9}$ & 0.22 & 0.60 & $\mathbf{0 . 0 6}$ & 0.15 & 0.49 \\
\hline Empathy Quotient & $\mathbf{0 . 2 2}$ & 0.05 & 0.22 & $\mathbf{0 . 2 2}$ & 0.22 & 0.60 & $\mathbf{0 . 0 2}$ & 0.10 & 0.57 \\
\hline PANAS-Positive & $\mathbf{0 . 2 0}$ & 0.04 & 0.27 & $\mathbf{0 . 1 8}$ & 0.18 & 0.60 & $\mathbf{0 . 0 2}$ & 0.08 & 0.59 \\
\hline MSCEIT: Strategic & $\mathbf{0 . 0 9}$ & 0.05 & 0.67 & $\mathbf{0 . 0 9}$ & 0.22 & 0.60 & $\mathbf{- 0 . 0 1}$ & 0.05 & 0.76 \\
\hline Education & $\mathbf{0 . 0 8}$ & 0.04 & 0.67 & $\mathbf{0 . 0 5}$ & 0.19 & 0.60 & $\mathbf{- 0 . 0 1}$ & 0.04 & 0.76 \\
\hline $\begin{array}{l}\text { Perceptual } \\
\text { Reasoning }\end{array}$ & $\mathbf{0 . 0 6}$ & 0.05 & 0.72 & $\mathbf{- 0 . 0 1}$ & 0.21 & 0.64 & $\mathbf{- 0 . 0 2}$ & 0.04 & 0.76 \\
\hline PANAS-Negative & $\mathbf{0 . 0 0}$ & 0.04 & 1.00 & $\mathbf{- 0 . 1 3}$ & 0.14 & 0.76 & $\mathbf{- 0 . 0 1}$ & 0.02 & 0.76 \\
\hline Age & $\mathbf{0 . 0 0}$ & 0.07 & 1.00 & $\mathbf{- 0 . 2 1}$ & 0.16 & 0.81 & $\mathbf{- 0 . 0 4}$ & 0.05 & 0.77 \\
\hline $\begin{array}{l}\text { Verbal } \\
\text { Comprehension }\end{array}$ & $\mathbf{- 0 . 0 5}$ & 0.06 & 0.73 & $\mathbf{- 0 . 0 6}$ & 0.21 & 0.68 & $\mathbf{- 0 . 0 2}$ & 0.04 & 0.76 \\
\hline $\begin{array}{l}\text { MSCEIT: } \\
\text { Experiential }\end{array}$ & $\mathbf{- 0 . 0 8}$ & 0.06 & 0.67 & $\mathbf{- 0 . 0 2}$ & 0.25 & 0.64 & $\mathbf{- 0 . 0 3}$ & 0.06 & 0.76 \\
\hline 16PF: Self-Control & $\mathbf{- 0 . 0 8}$ & 0.05 & 0.67 & $\mathbf{0 . 0 5}$ & 0.21 & 0.60 & $\mathbf{- 0 . 0 1}$ & 0.04 & 0.76 \\
\hline Depression & $\mathbf{- 0 . 1 2}$ & 0.05 & 0.59 & $\mathbf{0 . 1 0}$ & 0.23 & 0.60 & $\mathbf{- 0 . 0 1}$ & 0.06 & 0.76 \\
\hline $\begin{array}{l}\text { 16PF: Tough- } \\
\text { Mindedness }\end{array}$ & $\mathbf{- 0 . 1 5}$ & 0.05 & 0.41 & $\mathbf{0 . 1 5}$ & 0.19 & 0.60 & $\mathbf{0 . 0 1}$ & 0.06 & 0.76 \\
\hline 16PF: Anxiety & $\mathbf{- 0 . 1 6}$ & 0.05 & 0.41 & $\mathbf{0 . 1 4}$ & 0.21 & 0.60 & $\mathbf{0 . 0 0}$ & 0.07 & 0.76 \\
\hline Perceived Stress & $\mathbf{- 0 . 2 2}$ & 0.05 & 0.22 & $\mathbf{0 . 2 2}$ & 0.18 & 0.60 & $\mathbf{0 . 0 3}$ & 0.08 & 0.57 \\
\hline STAI-Trait & $\mathbf{- 0 . 2 5}$ & 0.04 & 0.13 & $\mathbf{0 . 2 5}$ & 0.19 & 0.60 & $\mathbf{0 . 0 5}$ & 0.10 & 0.49 \\
\hline
\end{tabular}




\section{Appendix D. Predicting SNI with GMV and all other features using Framework 3.}

2 The model coefficients and accuracies (assessed with both Pearson's $r$ and prediction $R^{2}$ ) with

3 SDs and p-values corrected for FDR obtained from Framework 3.

\begin{tabular}{|c|c|c|c|c|c|c|c|c|c|}
\hline Features & coeff & $\begin{array}{l}\text { coeff- } \\
\text { SD }\end{array}$ & coeff-p & $\mathbf{r}$ & $r-S D$ & $r-p$ & R2 & $\begin{array}{l}\text { R2- } \\
\text { SD }\end{array}$ & $R 2-p$ \\
\hline 16PF_Extraversion & 0.36 & 0.04 & 0.13 & 0.35 & 0.18 & 0.78 & 0.10 & 0.13 & 0.77 \\
\hline 16PF_Independence & 0.31 & 0.05 & 0.44 & 0.29 & 0.23 & 0.78 & 0.06 & 0.16 & 0.77 \\
\hline L-Accumbens-area & 0.23 & 0.05 & 0.89 & 0.23 & 0.20 & 0.78 & 0.03 & 0.09 & 0.77 \\
\hline Empathy Quotient & 0.22 & 0.05 & 0.89 & 0.20 & 0.22 & 0.78 & 0.02 & 0.10 & 0.77 \\
\hline PANAS-Positive & 0.20 & 0.04 & 0.89 & 0.19 & 0.18 & 0.78 & 0.02 & 0.08 & 0.77 \\
\hline L-Middle-temporal-G & 0.19 & 0.05 & 0.89 & 0.17 & 0.19 & 0.78 & 0.01 & 0.08 & 0.77 \\
\hline $\begin{array}{l}\text { L-Planum-temporale-superior- } \\
\text { temporal-G }\end{array}$ & 0.18 & 0.06 & 0.89 & 0.17 & 0.25 & 0.78 & 0.00 & 0.10 & 0.77 \\
\hline R-Caudate & 0.17 & 0.06 & 0.89 & 0.17 & 0.23 & 0.78 & 0.00 & 0.09 & 0.77 \\
\hline L-Anterior-circular-S-insula & 0.17 & 0.06 & 0.89 & 0.12 & 0.25 & 0.78 & -0.02 & 0.09 & 0.77 \\
\hline L-Caudate & 0.15 & 0.06 & 0.89 & 0.15 & 0.23 & 0.78 & -0.01 & 0.08 & 0.77 \\
\hline $\begin{array}{l}\text { L-Posterior-dorsal-cingulate- } \\
\text { G_dPCC }\end{array}$ & 0.14 & 0.06 & 0.89 & 0.10 & 0.23 & 0.78 & -0.01 & 0.07 & 0.77 \\
\hline R-Superior-precentral-S & 0.13 & 0.06 & 0.89 & 0.07 & 0.24 & 0.78 & -0.02 & 0.07 & 0.77 \\
\hline L-Amygdala & 0.12 & 0.06 & 0.89 & 0.10 & 0.24 & 0.78 & -0.02 & 0.07 & 0.77 \\
\hline R-Orbital-inferior-frontal-G & 0.11 & 0.05 & 0.89 & 0.10 & 0.20 & 0.78 & -0.01 & 0.05 & 0.77 \\
\hline R-Pallidum & 0.11 & 0.05 & 0.89 & 0.10 & 0.21 & 0.78 & -0.01 & 0.06 & 0.77 \\
\hline MSCEIT_Strategic & 0.09 & 0.05 & 0.92 & 0.07 & 0.23 & 0.78 & -0.01 & 0.05 & 0.77 \\
\hline R-Amygdala & 0.09 & 0.06 & 0.93 & 0.03 & 0.24 & 0.78 & -0.02 & 0.06 & 0.77 \\
\hline R-Suborbital-S & 0.08 & 0.05 & 0.96 & 0.02 & 0.22 & 0.78 & -0.02 & 0.05 & 0.77 \\
\hline Education & 0.08 & 0.04 & 0.96 & 0.05 & 0.19 & 0.78 & -0.01 & 0.03 & 0.77 \\
\hline L-Supramarginal-G & 0.07 & 0.06 & 0.96 & -0.02 & 0.24 & 0.78 & -0.02 & 0.05 & 0.77 \\
\hline $\begin{array}{l}\text { L-Middle-anterior-cingulate- } \\
\text { G\&S_aMCC }\end{array}$ & 0.07 & 0.04 & 0.97 & 0.02 & 0.20 & 0.78 & -0.01 & 0.03 & 0.77 \\
\hline Perceptual Reasoning & 0.06 & 0.05 & 0.97 & -0.02 & 0.21 & 0.78 & -0.02 & 0.04 & 0.77 \\
\hline L-Medial-orbital-S & 0.06 & 0.05 & 0.97 & -0.02 & 0.21 & 0.78 & -0.02 & 0.04 & 0.77 \\
\hline R-Triangular-inferior-frontal-G & 0.05 & 0.05 & 0.98 & -0.03 & 0.19 & 0.78 & -0.02 & 0.03 & 0.77 \\
\hline R-Lateral-orbital-S & 0.05 & 0.05 & 0.98 & -0.04 & 0.19 & 0.78 & -0.02 & 0.03 & 0.77 \\
\hline R-Anterior-transverse-temporal-G & 0.05 & 0.05 & 0.98 & -0.06 & 0.19 & 0.78 & -0.02 & 0.03 & 0.77 \\
\hline L-Pericallosal-S & 0.05 & 0.05 & 0.98 & -0.07 & 0.20 & 0.78 & -0.02 & 0.03 & 0.77 \\
\hline L-Pallidum & 0.04 & 0.06 & 0.98 & -0.10 & 0.21 & 0.78 & -0.03 & 0.04 & 0.77 \\
\hline R-Inferior-temporal-G & 0.04 & 0.06 & 0.98 & -0.10 & 0.19 & 0.78 & -0.03 & 0.04 & 0.77 \\
\hline R-Anterior-circular-S-insula & 0.04 & 0.06 & 0.98 & -0.10 & 0.21 & 0.78 & -0.02 & 0.04 & 0.77 \\
\hline R-Inferior-temporal-S & 0.04 & 0.05 & 0.98 & -0.07 & 0.19 & 0.78 & -0.02 & 0.03 & 0.77 \\
\hline R-Hippocampus & 0.04 & 0.05 & 0.98 & -0.10 & 0.19 & 0.78 & -0.02 & 0.03 & 0.77 \\
\hline $\begin{array}{l}\text { R-Posterior-dorsal-cingulate- } \\
\text { G_dPCC }\end{array}$ & 0.03 & 0.04 & 0.98 & -0.08 & 0.16 & 0.78 & -0.02 & 0.03 & 0.77 \\
\hline
\end{tabular}




\begin{tabular}{|c|c|c|c|c|c|c|c|c|c|}
\hline L-Inferior-temporal-S & 0.03 & 0.05 & 0.98 & -0.10 & 0.17 & 0.78 & -0.02 & 0.03 & 0.77 \\
\hline L-Occipital-pole & 0.03 & 0.06 & 0.98 & -0.16 & 0.19 & 0.78 & -0.03 & 0.05 & 0.77 \\
\hline R-Precuneus & 0.03 & 0.05 & 0.98 & -0.14 & 0.16 & 0.78 & -0.02 & 0.03 & 0.77 \\
\hline R-Lateral-superior-temporal-G & 0.03 & 0.05 & 0.98 & -0.12 & 0.17 & 0.78 & -0.02 & 0.03 & 0.77 \\
\hline R-Subparietal-S & 0.02 & 0.05 & 0.98 & -0.13 & 0.15 & 0.78 & -0.02 & 0.03 & 0.77 \\
\hline $\begin{array}{l}\text { L-Middle-posterior-cingulate- } \\
\text { G\&S_pMCC }\end{array}$ & 0.02 & 0.05 & 0.98 & -0.14 & 0.15 & 0.78 & -0.02 & 0.03 & 0.77 \\
\hline $\begin{array}{l}\text { R-Planum-polare-superior- } \\
\text { temporal-G }\end{array}$ & 0.02 & 0.05 & 0.98 & -0.13 & 0.14 & 0.78 & -0.02 & 0.02 & 0.77 \\
\hline L-Subcallosal-G & 0.02 & 0.05 & 0.98 & -0.13 & 0.14 & 0.78 & -0.02 & 0.02 & 0.77 \\
\hline L-Lateral-superior-temporal-G & 0.02 & 0.05 & 0.98 & -0.14 & 0.14 & 0.78 & -0.02 & 0.03 & 0.77 \\
\hline R-Pericallosal-S & 0.02 & 0.05 & 0.98 & -0.15 & 0.15 & 0.78 & -0.02 & 0.03 & 0.77 \\
\hline L-Subparietal-S & 0.01 & 0.06 & 0.98 & -0.17 & 0.16 & 0.78 & -0.03 & 0.04 & 0.77 \\
\hline L-Frontomarginal-G\&S & 0.01 & 0.06 & 0.99 & -0.19 & 0.15 & 0.79 & -0.03 & 0.04 & 0.77 \\
\hline R-Middle-temporal-G & 0.01 & 0.04 & 0.98 & -0.12 & 0.12 & 0.78 & -0.01 & 0.02 & 0.77 \\
\hline R-Inferior-frontal-S & 0.01 & 0.05 & 0.99 & -0.17 & 0.14 & 0.78 & -0.02 & 0.03 & 0.77 \\
\hline L-Middle-frontal-S & 0.01 & 0.06 & 0.99 & -0.17 & 0.14 & 0.78 & -0.03 & 0.03 & 0.77 \\
\hline L-S-intermedius-primus & 0.00 & 0.06 & 1.00 & -0.17 & 0.14 & 0.78 & -0.03 & 0.03 & 0.77 \\
\hline $\begin{array}{l}\text { R-Anterior-occipital-S\&preoccipital- } \\
\text { notch }\end{array}$ & 0.00 & 0.05 & 1.00 & -0.14 & 0.12 & 0.78 & -0.02 & 0.03 & 0.77 \\
\hline R-Central-S & 0.00 & 0.06 & 1.00 & -0.18 & 0.14 & 0.78 & -0.03 & 0.04 & 0.77 \\
\hline R-Superior-temporal-S & 0.00 & 0.06 & 1.00 & -0.18 & 0.14 & 0.78 & -0.03 & 0.04 & 0.77 \\
\hline Age & 0.00 & 0.07 & 1.00 & -0.21 & 0.16 & 0.81 & -0.04 & 0.05 & 0.78 \\
\hline PANAS-Negative & 0.00 & 0.04 & 1.00 & -0.14 & 0.13 & 0.78 & -0.01 & 0.02 & 0.77 \\
\hline L-Postcentral-G & 0.00 & 0.06 & 1.00 & -0.17 & 0.14 & 0.78 & -0.03 & 0.03 & 0.77 \\
\hline L-Middle-occipital-S\&lunatus-S & -0.01 & 0.05 & 1.00 & -0.15 & 0.13 & 0.78 & -0.02 & 0.03 & 0.77 \\
\hline L-Lateral-orbital-S & -0.01 & 0.05 & 1.00 & -0.15 & 0.14 & 0.78 & -0.02 & 0.03 & 0.77 \\
\hline L-Putamen & -0.01 & 0.06 & 0.98 & -0.17 & 0.15 & 0.78 & -0.03 & 0.04 & 0.77 \\
\hline R-Medial-orbital-S & -0.01 & 0.05 & 0.98 & -0.15 & 0.14 & 0.78 & -0.02 & 0.03 & 0.77 \\
\hline R-Lateral-occipitotemporal-G & -0.01 & 0.06 & 0.98 & -0.17 & 0.15 & 0.78 & -0.03 & 0.04 & 0.77 \\
\hline L-Inferior-temporal-G & -0.02 & 0.05 & 0.98 & -0.15 & 0.15 & 0.78 & -0.02 & 0.03 & 0.77 \\
\hline L-Long-insular-G\&central-insula-S & -0.02 & 0.05 & 0.98 & -0.14 & 0.14 & 0.78 & -0.02 & 0.03 & 0.77 \\
\hline L-Precuneus & -0.02 & 0.06 & 0.98 & -0.16 & 0.16 & 0.78 & -0.03 & 0.04 & 0.77 \\
\hline L-Angular-G & -0.02 & 0.06 & 0.98 & -0.17 & 0.16 & 0.78 & -0.03 & 0.04 & 0.77 \\
\hline R-Frontomarginal-G\&S & -0.02 & 0.06 & 0.98 & -0.17 & 0.16 & 0.78 & -0.03 & 0.04 & 0.77 \\
\hline R-Supramarginal-G & -0.02 & 0.05 & 0.98 & -0.13 & 0.15 & 0.78 & -0.02 & 0.03 & 0.77 \\
\hline $\begin{array}{l}\text { R-Middle-posterior-cingulate- } \\
\text { G\&S_pMCC }\end{array}$ & -0.02 & 0.06 & 0.98 & -0.15 & 0.17 & 0.78 & -0.03 & 0.04 & 0.77 \\
\hline R-S-intermedius-primus & -0.02 & 0.06 & 0.98 & -0.15 & 0.16 & 0.78 & -0.03 & 0.04 & 0.77 \\
\hline L-Posterior-lateral-S & -0.02 & 0.07 & 0.98 & -0.18 & 0.17 & 0.78 & -0.03 & 0.05 & 0.77 \\
\hline L-Superior-precentral-S & -0.02 & 0.04 & 0.98 & -0.10 & 0.15 & 0.78 & -0.01 & 0.02 & 0.77 \\
\hline $\begin{array}{l}\text { R-Superior-occipital-S\&transverse- } \\
\text { occipital-S }\end{array}$ & -0.02 & 0.04 & 0.98 & -0.11 & 0.15 & 0.78 & -0.02 & 0.03 & 0.77 \\
\hline R-Short-insular-G & -0.03 & 0.06 & 0.98 & -0.15 & 0.17 & 0.78 & -0.03 & 0.04 & 0.77 \\
\hline R-Lateral-occipitotemporal-S & -0.03 & 0.05 & 0.98 & -0.10 & 0.16 & 0.78 & -0.02 & 0.03 & 0.77 \\
\hline
\end{tabular}




\begin{tabular}{|c|c|c|c|c|c|c|c|c|c|}
\hline $\begin{array}{l}\text { L-Anterior-occipital-S\&preoccipital- } \\
\text { notch }\end{array}$ & -0.03 & 0.04 & 0.98 & -0.09 & 0.16 & 0.78 & -0.02 & 0.02 & 0.77 \\
\hline L-Superior-temporal-S & -0.03 & 0.06 & 0.98 & -0.13 & 0.18 & 0.78 & -0.03 & 0.04 & 0.77 \\
\hline $\begin{array}{l}\text { L-Planum-polare-superior- } \\
\text { temporal-G }\end{array}$ & -0.04 & 0.05 & 0.98 & -0.10 & 0.18 & 0.78 & -0.02 & 0.03 & 0.77 \\
\hline R-Postcentral-G & -0.04 & 0.06 & 0.98 & -0.13 & 0.19 & 0.78 & -0.03 & 0.04 & 0.77 \\
\hline L-Superior-occipital-G & -0.04 & 0.05 & 0.98 & -0.09 & 0.18 & 0.78 & -0.02 & 0.03 & 0.77 \\
\hline L-Middle-occipital-G & -0.04 & 0.05 & 0.98 & -0.10 & 0.19 & 0.78 & -0.02 & 0.04 & 0.77 \\
\hline L-Anterior-transverse-temporal-G & -0.04 & 0.05 & 0.98 & -0.09 & 0.18 & 0.78 & -0.02 & 0.03 & 0.77 \\
\hline R-Anterior-cingulate-G\&S_ACC & -0.04 & 0.05 & 0.98 & -0.07 & 0.19 & 0.78 & -0.02 & 0.03 & 0.77 \\
\hline L-Central-S & -0.04 & 0.04 & 0.98 & -0.04 & 0.18 & 0.78 & -0.01 & 0.03 & 0.77 \\
\hline R-Middle-occipital-G & -0.04 & 0.04 & 0.98 & -0.04 & 0.18 & 0.78 & -0.01 & 0.03 & 0.77 \\
\hline R-Transverse-frontopolar-G\&S & -0.04 & 0.05 & 0.98 & -0.07 & 0.18 & 0.78 & -0.02 & 0.03 & 0.77 \\
\hline R-Putamen & -0.05 & 0.05 & 0.98 & -0.07 & 0.21 & 0.78 & -0.02 & 0.04 & 0.77 \\
\hline L-Subcentral-G\&S & -0.05 & 0.06 & 0.98 & -0.08 & 0.22 & 0.78 & -0.03 & 0.04 & 0.77 \\
\hline Brain-Stem & -0.05 & 0.06 & 0.98 & -0.08 & 0.20 & 0.78 & -0.03 & 0.04 & 0.77 \\
\hline $\begin{array}{l}\text { L-parahippocampal-medial- } \\
\text { occipitotemporal-G }\end{array}$ & -0.05 & 0.05 & 0.98 & -0.04 & 0.21 & 0.78 & -0.02 & 0.04 & 0.77 \\
\hline Verbal Comprehension & -0.05 & 0.06 & 0.98 & -0.07 & 0.21 & 0.78 & -0.03 & 0.04 & 0.77 \\
\hline L-Cerebellum-Cortex & -0.05 & 0.06 & 0.98 & -0.09 & 0.22 & 0.78 & -0.03 & 0.05 & 0.77 \\
\hline L-Marginal-cingulate-S & -0.06 & 0.05 & 0.98 & -0.05 & 0.23 & 0.78 & -0.02 & 0.04 & 0.77 \\
\hline R-Accumbens-area & -0.06 & 0.05 & 0.98 & -0.07 & 0.21 & 0.78 & -0.02 & 0.04 & 0.77 \\
\hline $\begin{array}{l}\text { R-Planum-temporale-superior- } \\
\text { temporal-G }\end{array}$ & -0.06 & 0.05 & 0.97 & -0.03 & 0.21 & 0.78 & -0.02 & 0.04 & 0.77 \\
\hline L-Superior-frontal-G & -0.06 & 0.05 & 0.98 & -0.03 & 0.22 & 0.78 & -0.02 & 0.04 & 0.77 \\
\hline R-Posterior-lateral-S & -0.06 & 0.04 & 0.97 & 0.00 & 0.19 & 0.78 & -0.01 & 0.03 & 0.77 \\
\hline R-Middle-frontal-G & -0.07 & 0.07 & 0.97 & -0.06 & 0.26 & 0.78 & -0.03 & 0.06 & 0.77 \\
\hline L-Hippocampus & -0.07 & 0.05 & 0.96 & 0.00 & 0.22 & 0.78 & -0.02 & 0.04 & 0.77 \\
\hline $\begin{array}{l}\text { L-Posterior-ventral-cingulate- } \\
\text { G_vPCC }\end{array}$ & -0.07 & 0.04 & 0.96 & 0.05 & 0.18 & 0.78 & -0.01 & 0.03 & 0.77 \\
\hline R-Postcentral-S & -0.07 & 0.06 & 0.96 & -0.01 & 0.23 & 0.78 & -0.02 & 0.05 & 0.77 \\
\hline R-Superior-occipital-G & -0.07 & 0.05 & 0.96 & 0.02 & 0.21 & 0.78 & -0.01 & 0.04 & 0.77 \\
\hline $\begin{array}{l}\text { L-Intraparietal-S\&transverse- } \\
\text { parietal-S }\end{array}$ & -0.07 & 0.05 & 0.96 & 0.00 & 0.23 & 0.78 & -0.02 & 0.05 & 0.77 \\
\hline L-Middle-frontal-G & -0.07 & 0.07 & 0.96 & -0.04 & 0.25 & 0.78 & -0.03 & 0.06 & 0.77 \\
\hline L-Opercular-inferior-frontal-G & -0.08 & 0.05 & 0.96 & 0.04 & 0.22 & 0.78 & -0.01 & 0.04 & 0.77 \\
\hline 16PF_Self-Control & -0.08 & 0.05 & 0.96 & 0.04 & 0.22 & 0.78 & -0.01 & 0.04 & 0.77 \\
\hline MSCEIT_Experiential & -0.08 & 0.06 & 0.96 & -0.01 & 0.25 & 0.78 & -0.03 & 0.06 & 0.77 \\
\hline R-Superior-frontal-S & -0.08 & 0.05 & 0.94 & 0.03 & 0.23 & 0.78 & -0.02 & 0.05 & 0.77 \\
\hline R-Inferior-circular-S-insula & -0.08 & 0.06 & 0.93 & 0.03 & 0.24 & 0.78 & -0.02 & 0.05 & 0.77 \\
\hline R-Occipital-pole & -0.08 & 0.06 & 0.93 & 0.03 & 0.22 & 0.78 & -0.02 & 0.05 & 0.77 \\
\hline $\begin{array}{l}\text { L-Medial-occipitotemporal- } \\
\text { S\&lingual-S }\end{array}$ & -0.08 & 0.05 & 0.93 & 0.04 & 0.20 & 0.78 & -0.01 & 0.04 & 0.77 \\
\hline L-Inferior-frontal-S & -0.09 & 0.04 & 0.93 & 0.08 & 0.18 & 0.78 & -0.01 & 0.04 & 0.77 \\
\hline R-Transverse-temporal-S & -0.09 & 0.12 & 0.93 & -0.07 & 0.35 & 0.78 & -0.07 & 0.15 & 0.89 \\
\hline R-Parieto-occipital-S & -0.09 & 0.06 & 0.93 & 0.04 & 0.25 & 0.78 & -0.02 & 0.06 & 0.77 \\
\hline
\end{tabular}




\begin{tabular}{|c|c|c|c|c|c|c|c|c|c|}
\hline R-Superior-parietal-lobule & -0.09 & 0.06 & 0.93 & 0.04 & 0.23 & 0.78 & -0.02 & 0.06 & 0.77 \\
\hline L-Posterior-transverse-collateral-S & -0.09 & 0.05 & 0.92 & 0.06 & 0.21 & 0.78 & -0.01 & 0.05 & 0.77 \\
\hline R-Precentral-G & -0.10 & 0.05 & 0.92 & 0.08 & 0.20 & 0.78 & -0.01 & 0.05 & 0.77 \\
\hline R-Angular-G & -0.10 & 0.07 & 0.92 & 0.00 & 0.27 & 0.78 & -0.03 & 0.07 & 0.77 \\
\hline R-Orbital-G & -0.10 & 0.05 & 0.92 & 0.07 & 0.22 & 0.78 & -0.01 & 0.05 & 0.77 \\
\hline $\begin{array}{l}\text { L-Superior-occipital-S\&transverse- } \\
\text { occipital-S }\end{array}$ & -0.10 & 0.05 & 0.92 & 0.07 & 0.20 & 0.78 & -0.01 & 0.04 & 0.77 \\
\hline R-Middle-frontal-S & -0.10 & 0.05 & 0.92 & 0.06 & 0.22 & 0.78 & -0.01 & 0.05 & 0.77 \\
\hline L-Transverse-temporal-S & -0.10 & 0.04 & 0.92 & 0.08 & 0.19 & 0.78 & -0.01 & 0.04 & 0.77 \\
\hline L-Orbital-G & -0.10 & 0.05 & 0.92 & 0.08 & 0.21 & 0.78 & -0.01 & 0.05 & 0.77 \\
\hline R-Cerebellum-Cortex & -0.10 & 0.06 & 0.92 & 0.02 & 0.25 & 0.78 & -0.03 & 0.07 & 0.77 \\
\hline L-Lateral-occipitotemporal-S & -0.11 & 0.05 & 0.91 & 0.09 & 0.21 & 0.78 & -0.01 & 0.05 & 0.77 \\
\hline $\begin{array}{l}\text { R-Middle-anterior-cingulate- } \\
\text { G\&S_aMCC }\end{array}$ & -0.11 & 0.05 & 0.89 & 0.06 & 0.22 & 0.78 & -0.02 & 0.06 & 0.77 \\
\hline R-Anterior-transverse-collateral-S & -0.11 & 0.07 & 0.89 & 0.08 & 0.27 & 0.78 & -0.02 & 0.08 & 0.77 \\
\hline R-Horizontal-anterior-lateral-S & -0.11 & 0.05 & 0.89 & 0.13 & 0.20 & 0.78 & 0.00 & 0.05 & 0.77 \\
\hline L-Anterior-cingulate-G\&S_ACC & -0.11 & 0.05 & 0.89 & 0.09 & 0.23 & 0.78 & -0.01 & 0.06 & 0.77 \\
\hline $\begin{array}{l}\text { R-Intraparietal-S\&transverse- } \\
\text { parietal-S }\end{array}$ & -0.11 & 0.05 & 0.89 & 0.10 & 0.20 & 0.78 & -0.01 & 0.05 & 0.77 \\
\hline R-Long-insular-G\&central-insula-S & -0.11 & 0.05 & 0.89 & 0.11 & 0.20 & 0.78 & -0.01 & 0.05 & 0.77 \\
\hline R-Subcentral-G\&S & -0.11 & 0.05 & 0.89 & 0.11 & 0.20 & 0.78 & -0.01 & 0.05 & 0.77 \\
\hline R-Marginal-cingulate-S & -0.11 & 0.07 & 0.89 & 0.09 & 0.25 & 0.78 & -0.02 & 0.07 & 0.77 \\
\hline L-Superior-circular-S-insula & -0.11 & 0.05 & 0.89 & 0.08 & 0.23 & 0.78 & -0.01 & 0.06 & 0.77 \\
\hline R-Temporal-pole & -0.11 & 0.05 & 0.89 & 0.11 & 0.22 & 0.78 & -0.01 & 0.06 & 0.77 \\
\hline L-Horizontal-anterior-lateral-S & -0.12 & 0.05 & 0.89 & 0.07 & 0.20 & 0.78 & -0.01 & 0.05 & 0.77 \\
\hline L-Short-insular-G & -0.12 & 0.06 & 0.89 & 0.10 & 0.23 & 0.78 & -0.01 & 0.06 & 0.77 \\
\hline L-Inferior-precentral-S & -0.12 & 0.05 & 0.89 & 0.10 & 0.20 & 0.78 & -0.01 & 0.05 & 0.77 \\
\hline Beck Depression Inventory & -0.12 & 0.06 & 0.89 & 0.09 & 0.24 & 0.78 & -0.01 & 0.07 & 0.77 \\
\hline R-Inferior-occipital-G\&S & -0.12 & 0.05 & 0.89 & 0.09 & 0.20 & 0.78 & -0.01 & 0.06 & 0.77 \\
\hline R-Subcallosal-G & -0.12 & 0.06 & 0.89 & 0.07 & 0.23 & 0.78 & -0.02 & 0.06 & 0.77 \\
\hline L-Cuneus & -0.12 & 0.06 & 0.89 & 0.07 & 0.25 & 0.78 & -0.02 & 0.07 & 0.77 \\
\hline L-Orbital-S & -0.12 & 0.05 & 0.89 & 0.12 & 0.19 & 0.78 & 0.00 & 0.05 & 0.77 \\
\hline R-Superior-circular-S-insula & -0.12 & 0.06 & 0.89 & 0.10 & 0.23 & 0.78 & -0.01 & 0.06 & 0.77 \\
\hline L-Superior-parietal-lobule & -0.12 & 0.05 & 0.89 & 0.09 & 0.22 & 0.78 & -0.01 & 0.07 & 0.77 \\
\hline R-Inferior-precentral-S & -0.12 & 0.04 & 0.89 & 0.13 & 0.17 & 0.78 & 0.00 & 0.05 & 0.77 \\
\hline L-Postcentral-S & -0.13 & 0.07 & 0.89 & 0.10 & 0.26 & 0.78 & -0.02 & 0.08 & 0.77 \\
\hline L-Thalamus-Proper & -0.13 & 0.05 & 0.89 & 0.11 & 0.20 & 0.78 & -0.01 & 0.06 & 0.77 \\
\hline L-Orbital-inferior-frontal-G & -0.13 & 0.06 & 0.89 & 0.10 & 0.25 & 0.78 & -0.01 & 0.07 & 0.77 \\
\hline L-Transverse-frontopolar-G\&S & -0.13 & 0.05 & 0.89 & 0.13 & 0.21 & 0.78 & 0.00 & 0.06 & 0.77 \\
\hline L-Precentral-G & -0.14 & 0.05 & 0.89 & 0.14 & 0.21 & 0.78 & 0.00 & 0.07 & 0.77 \\
\hline R-Posterior-transverse-collateral-S & -0.14 & 0.05 & 0.89 & 0.13 & 0.19 & 0.78 & 0.00 & 0.06 & 0.77 \\
\hline $\begin{array}{l}\text { R-parahippocampal-medial- } \\
\text { occipitotemporal-G }\end{array}$ & -0.14 & 0.05 & 0.89 & 0.14 & 0.19 & 0.78 & 0.00 & 0.06 & 0.77 \\
\hline $\begin{array}{l}\text { R-Medial-occipitotemporal- } \\
\text { S\&lingual-S }\end{array}$ & -0.14 & 0.06 & 0.89 & 0.11 & 0.23 & 0.78 & -0.01 & 0.07 & 0.77 \\
\hline R-Calcarine-S & -0.14 & 0.05 & 0.89 & 0.13 & 0.20 & 0.78 & 0.00 & 0.06 & 0.77 \\
\hline
\end{tabular}




\begin{tabular}{|c|c|c|c|c|c|c|c|c|c|}
\hline L-Lateral-occipitotemporal-G & -0.14 & 0.05 & 0.89 & 0.13 & 0.21 & 0.78 & 0.00 & 0.07 & 0.77 \\
\hline R-Orbital-S & -0.14 & 0.06 & 0.89 & 0.12 & 0.23 & 0.78 & -0.01 & 0.08 & 0.77 \\
\hline L-Superior-frontal-S & -0.15 & 0.05 & 0.89 & 0.14 & 0.19 & 0.78 & 0.00 & 0.06 & 0.77 \\
\hline L-Vertical-anterior-lateral-S & -0.15 & 0.07 & 0.89 & 0.10 & 0.27 & 0.78 & -0.02 & 0.10 & 0.77 \\
\hline L-Suborbital-S & -0.15 & 0.04 & 0.89 & 0.14 & 0.17 & 0.78 & 0.01 & 0.05 & 0.77 \\
\hline R-Paracentral-lobule\&S & -0.15 & 0.05 & 0.89 & 0.15 & 0.18 & 0.78 & 0.01 & 0.06 & 0.77 \\
\hline 16PF_Tough-Mindedness & -0.15 & 0.04 & 0.89 & 0.16 & 0.19 & 0.78 & 0.01 & 0.06 & 0.77 \\
\hline R-Straight-G & -0.15 & 0.05 & 0.89 & 0.15 & 0.21 & 0.78 & 0.00 & 0.07 & 0.77 \\
\hline L-Parieto-occipital-S & -0.15 & 0.05 & 0.89 & 0.16 & 0.20 & 0.78 & 0.01 & 0.07 & 0.77 \\
\hline R-Middle-occipital-S\&lunatus-S & -0.16 & 0.05 & 0.89 & 0.14 & 0.20 & 0.78 & 0.00 & 0.07 & 0.77 \\
\hline L-Ligual-medial-occipitotemporal-G & -0.16 & 0.05 & 0.89 & 0.15 & 0.21 & 0.78 & 0.00 & 0.07 & 0.77 \\
\hline R-Opercular-inferior-frontal-G & -0.16 & 0.04 & 0.89 & 0.16 & 0.18 & 0.78 & 0.01 & 0.06 & 0.77 \\
\hline R-Thalamus-Proper & -0.16 & 0.06 & 0.89 & 0.15 & 0.23 & 0.78 & 0.00 & 0.08 & 0.77 \\
\hline 16PF_Anxiety & -0.16 & 0.05 & 0.89 & 0.14 & 0.20 & 0.78 & 0.00 & 0.07 & 0.77 \\
\hline R-Superior-frontal-G & -0.16 & 0.05 & 0.89 & 0.16 & 0.20 & 0.78 & 0.00 & 0.07 & 0.77 \\
\hline L-Straight-G & -0.17 & 0.05 & 0.89 & 0.18 & 0.19 & 0.78 & 0.01 & 0.07 & 0.77 \\
\hline R-Vertical-anterior-lateral-S & -0.17 & 0.04 & 0.89 & 0.17 & 0.18 & 0.78 & 0.01 & 0.07 & 0.77 \\
\hline L-Triangular-inferior-frontal-G & -0.17 & 0.05 & 0.89 & 0.18 & 0.21 & 0.78 & 0.01 & 0.08 & 0.77 \\
\hline $\begin{array}{l}\text { R-Posterior-ventral-cingulate- } \\
\text { G_VPCC }\end{array}$ & -0.18 & 0.04 & 0.89 & 0.17 & 0.18 & 0.78 & 0.01 & 0.07 & 0.77 \\
\hline L-Calcarine-S & -0.18 & 0.05 & 0.89 & 0.18 & 0.20 & 0.78 & 0.01 & 0.08 & 0.77 \\
\hline L-Inferior-circular-S-insula & -0.18 & 0.04 & 0.89 & 0.18 & 0.17 & 0.78 & 0.02 & 0.06 & 0.77 \\
\hline R-Cuneus & -0.19 & 0.05 & 0.89 & 0.19 & 0.19 & 0.78 & 0.02 & 0.08 & 0.77 \\
\hline L-Anterior-transverse-collateral-S & -0.21 & 0.06 & 0.89 & 0.20 & 0.23 & 0.78 & 0.01 & 0.11 & 0.77 \\
\hline Perceived Stress & -0.22 & 0.04 & 0.89 & 0.22 & 0.18 & 0.78 & 0.03 & 0.08 & 0.77 \\
\hline L-Temporal-pole & -0.24 & 0.05 & 0.89 & 0.24 & 0.19 & 0.78 & 0.04 & 0.10 & 0.77 \\
\hline STAI-Trait & -0.26 & 0.04 & 0.79 & 0.25 & 0.18 & 0.78 & 0.05 & 0.10 & 0.77 \\
\hline L-Paracentral-lobule\&S & -0.29 & 0.05 & 0.44 & 0.29 & 0.19 & 0.78 & 0.07 & 0.12 & 0.77 \\
\hline R-Ligual-medial-occipitotemporal-G & -0.30 & 0.04 & 0.44 & 0.31 & 0.17 & 0.78 & 0.08 & 0.10 & 0.77 \\
\hline L-Inferior-occipital-G\&S & -0.35 & 0.04 & 0.13 & 0.34 & 0.18 & 0.78 & 0.10 & 0.13 & 0.77 \\
\hline
\end{tabular}




\section{Appendix E. Effect size and sample size estimation for every feature.}

2 The Pearson correlation between SNI and every demographic, psychological, and cortical and

3 subcortical GMV feature was computed to estimate effect size. The sample size for detecting the

4 effect of every feature was estimated assuming that only one effect is hypothesized and tested.

5 Abbreviations: L left, R right, G gyrus/gyri, S Sulcus/Sulci.

\begin{tabular}{|c|c|c|}
\hline Variables & Correlation with SNI & Sample Size Estimation \\
\hline \multicolumn{3}{|c|}{ Demographic Characteristics } \\
\hline Age & -0.0028916 & 938688 \\
\hline Gender & -0.0337893 & 6869 \\
\hline Education & 0.07748887 & 1301 \\
\hline \multicolumn{3}{|c|}{ Psychological measures } \\
\hline MSCEIT_Experiential & -0.0776123 & 1297 \\
\hline MSCEIT_Strategic & 0.09220126 & 917 \\
\hline 16PF_Extraversion & 0.35402236 & 57 \\
\hline 16PF_Independence & 0.3137471 & 74 \\
\hline 16PF_Tough.Mindedness & -0.1511065 & 338 \\
\hline 16PF_Self.Control & -0.076433 & 1338 \\
\hline 16PF_Anxiety & -0.1600565 & 300 \\
\hline Perceived Stress & -0.2191902 & 157 \\
\hline Beck Depression Inventory & -0.117672 & 561 \\
\hline PANAS_Positive & 0.19642275 & 198 \\
\hline PANAS_Negative & -0.0035564 & 620543 \\
\hline STAI_Trait & -0.2567068 & 113 \\
\hline Empathy Quotient & 0.21784528 & 160 \\
\hline Verbal Comprehension & -0.0550113 & 2588 \\
\hline Perceptual Reasoning & 0.06415813 & 1901 \\
\hline \multicolumn{3}{|c|}{ Cortical GMV in the Left Hemisphere } \\
\hline L-Frontomarginal-G\&S & 0.00918054 & 93120 \\
\hline L-Inferior-occipital-G\&S & -0.3494748 & 58 \\
\hline L-Paracentral-lobule\&S & -0.2907009 & 87 \\
\hline L-Subcentral-G\&S & -0.054361 & 2650 \\
\hline L-Transverse-frontopolar-G\&S & -0.1341769 & 430 \\
\hline L-Anterior-cingulate-G\&S_ACC & -0.1114413 & 626 \\
\hline L-Middle-anterior-cingulate-G\&S_aMCC & 0.06716702 & 1734 \\
\hline L-Middle-posterior-cingulate-G\&S_pMCC & 0.0185314 & 22850 \\
\hline
\end{tabular}




\begin{tabular}{|c|c|c|}
\hline L-Posterior-dorsal-cingulate-G_dPCC & 0.14093978 & 389 \\
\hline L-Posterior-ventral-cingulate-G_vPCC & -0.0671571 & 1734 \\
\hline L-Cuneus & -0.1195903 & 543 \\
\hline L-Opercular-inferior-frontal-G & -0.0770589 & 1316 \\
\hline L-Orbital-inferior-frontal-G & -0.1346853 & 427 \\
\hline L-Triangular-inferior-frontal-G & -0.1700251 & 266 \\
\hline L-Middle-frontal-G & -0.0758849 & 1357 \\
\hline L-Superior-frontal-G & -0.0597285 & 2194 \\
\hline L-Long-insular-G\&central-insula-S & -0.0173458 & 26081 \\
\hline L-Short-insular-G & -0.1154706 & 583 \\
\hline L-Middle-occipital-G & -0.0384255 & 5310 \\
\hline L-Superior-occipital-G & -0.036754 & 5804 \\
\hline L-Lateral-occipitotemporal-G & -0.1406978 & 391 \\
\hline L-Ligual-medial-occipitotemporal-G & -0.1581672 & 308 \\
\hline L-parahippocampal-medial-occipitotemporal-G & -0.0509749 & 3015 \\
\hline L-Orbital-G & -0.1029906 & 734 \\
\hline L-Angular-G & -0.0166132 & 28432 \\
\hline L-Supramarginal-G & 0.07104795 & 1549 \\
\hline L-Superior-parietal-lobule & -0.1200344 & 539 \\
\hline L-Postcentral-G & -0.0024642 & 1292603 \\
\hline L-Precentral-G & -0.1376735 & 408 \\
\hline L-Precuneus & -0.0176935 & 25066 \\
\hline L-Straight-G & -0.1659726 & 279 \\
\hline L-Subcallosal-G & 0.01509586 & 34436 \\
\hline L-Anterior-transverse-temporal-G & -0.0394119 & 5047 \\
\hline L-Lateral-superior-temporal-G & 0.01605985 & 30426 \\
\hline L-Planum-polare-superior-temporal-G & -0.0360494 & 6034 \\
\hline L-Planum-temporale-superior-temporal-G & 0.18072367 & 234 \\
\hline L-Inferior-temporal-G & -0.0155332 & 32524 \\
\hline L-Middle-temporal-G & 0.18989198 & 212 \\
\hline L-Horizontal-anterior-lateral-S & -0.1133548 & 605 \\
\hline L-Vertical-anterior-lateral-S & -0.14504 & 367 \\
\hline L-Posterior-lateral-S & -0.0224271 & 15599 \\
\hline L-Occipital-pole & 0.02742809 & 10427 \\
\hline L-Temporal-pole & -0.2367171 & 134 \\
\hline L-Calcarine-S & -0.1771533 & 244 \\
\hline L-Central-S & -0.0401729 & 4858 \\
\hline L-Marginal-cingulate-S & -0.0568431 & 2423 \\
\hline L-Anterior-circular-S-insula & 0.17041338 & 264 \\
\hline
\end{tabular}


bioRxiv preprint first posted online Dec. 27, 2019; doi: http://dx.doi.org/10.1101/2019.12.19.883173. The copyright holder for this preprint (which was not peer-reviewed) is the author/funder, who has granted bioRxiv a license to display the preprint in perpetuity.

It is made available under a CC-BY-NC-ND 4.0 International license.

\begin{tabular}{|c|c|c|}
\hline L-Inferior-circular-S-insula & -0.1812133 & 233 \\
\hline L-Superior-circular-S-insula & -0.1131711 & 607 \\
\hline L-Anterior-transverse-collateral-S & -0.2075977 & 176 \\
\hline L-Posterior-transverse-collateral-S & -0.0949917 & 864 \\
\hline L-Inferior-frontal-S & -0.0847298 & 1087 \\
\hline L-Middle-frontal-S & 0.00542848 & 266342 \\
\hline L-Superior-frontal-S & -0.1462755 & 361 \\
\hline L-S-intermedius-primus & 0.00539593 & 269566 \\
\hline L-Intraparietal-S\&transverse-parietal-S & -0.0729457 & 1469 \\
\hline L-Middle-occipital-S\&lunatus-S & -0.0078422 & 127618 \\
\hline L-Superior-occipital-S\&transverse-occipital-S & -0.097515 & 820 \\
\hline L-Anterior-occipital-S\&preoccipital-notch & -0.0322884 & 7523 \\
\hline L-Lateral-occipitotemporal-S & -0.1044436 & 714 \\
\hline L-Medial-occipitotemporal-S\&lingual-S & -0.085147 & 1077 \\
\hline L-Lateral-orbital-S & -0.011093 & 63778 \\
\hline L-Medial-orbital-S & 0.06266573 & 1993 \\
\hline L-Orbital-S & -0.1194376 & 544 \\
\hline L-Parieto-occipital-S & -0.1557196 & 318 \\
\hline L-Pericallosal-S & 0.04500085 & 3870 \\
\hline L-Postcentral-S & -0.1276236 & 476 \\
\hline L-Inferior-precentral-S & -0.1208256 & 532 \\
\hline L-Superior-precentral-S & -0.0239827 & 13640 \\
\hline L-Suborbital-S & -0.1456051 & 364 \\
\hline L-Subparietal-S & 0.0143831 & 37934 \\
\hline L-Inferior-temporal-S & 0.03142184 & 7944 \\
\hline L-Superior-temporal-S & -0.0340876 & 6749 \\
\hline L-Transverse-temporal-S & -0.1001802 & 776 \\
\hline \multicolumn{3}{|c|}{ Cortical GMV in the Right Hemisphere } \\
\hline R-Frontomarginal-G\&S & -0.0189623 & 21823 \\
\hline R-Inferior-occipital-G\&S & -0.1175469 & 562 \\
\hline R-Paracentral-lobule\&S & -0.1487712 & 349 \\
\hline R-Subcentral-G\&S & -0.109243 & 652 \\
\hline R-Transverse-frontopolar-G\&S & -0.0426377 & 4311 \\
\hline R-Anterior-cingulate-G\&S_ACC & -0.0416376 & 4521 \\
\hline R-Middle-anterior-cingulate-G\&S_aMCC & -0.1071467 & 678 \\
\hline R-Middle-posterior-cingulate-G\&S_pMCC & -0.0207774 & 18175 \\
\hline R-Posterior-dorsal-cingulate-G_dPCC & 0.03291939 & 7237 \\
\hline R-Posterior-ventral-cingulate-G_vPCC & -0.1752414 & 250 \\
\hline R-Cuneus & -0.184783 & 224 \\
\hline
\end{tabular}




\begin{tabular}{|c|c|c|}
\hline R-Opercular-inferior-frontal-G & -0.1580088 & 308 \\
\hline R-Orbital-inferior-frontal-G & 0.11117239 & 629 \\
\hline $\mathrm{R}$-Triangular-inferior-frontal-G & 0.05084247 & 3030 \\
\hline R-Middle-frontal-G & -0.0664817 & 1770 \\
\hline R-Superior-frontal-G & -0.1610238 & 297 \\
\hline R-Long-insular-G\&central-insula-S & -0.1106463 & 635 \\
\hline R-Short-insular-G & -0.0287966 & 9459 \\
\hline R-Middle-occipital-G & -0.0465737 & 3613 \\
\hline R-Superior-occipital-G & -0.0709251 & 1554 \\
\hline R-Lateral-occipitotemporal-G & -0.0149231 & 35238 \\
\hline R-Ligual-medial-occipitotemporal-G & -0.3020131 & 80 \\
\hline R-parahippocampal-medial-occipitotemporal-G & -0.1395864 & 397 \\
\hline R-Orbital-G & -0.0972696 & 824 \\
\hline R-Angular-G & -0.0943059 & 877 \\
\hline R-Supramarginal-G & -0.0194015 & 20846 \\
\hline R-Superior-parietal-lobule & -0.0922448 & 917 \\
\hline R-Postcentral-G & -0.0329844 & 7208 \\
\hline R-Precentral-G & -0.0939214 & 884 \\
\hline R-Precuneus & 0.02509895 & 12453 \\
\hline R-Straight-G & -0.1524617 & 332 \\
\hline R-Subcallosal-G & -0.1208282 & 532 \\
\hline R-Anterior-transverse-temporal-G & 0.04679593 & 3578 \\
\hline R-Lateral-superior-temporal-G & 0.02430314 & 13283 \\
\hline R-Planum-polare-superior-temporal-G & 0.01613924 & 30127 \\
\hline R-Planum-temporale-superior-temporal-G & -0.0613178 & 2082 \\
\hline R-Inferior-temporal-G & 0.04527234 & 3824 \\
\hline R-Middle-temporal-G & 0.00820435 & 116599 \\
\hline R-Horizontal-anterior-lateral-S & -0.1103838 & 638 \\
\hline R-Vertical-anterior-lateral-S & -0.1659003 & 279 \\
\hline R-Posterior-lateral-S & -0.0645492 & 1878 \\
\hline R-Occipital-pole & -0.0867708 & 1037 \\
\hline R-Temporal-pole & -0.1154087 & 583 \\
\hline R-Calcarine-S & -0.1395177 & 397 \\
\hline R-Central-S & 0.00131523 & 4537366 \\
\hline R-Marginal-cingulate-S & -0.1111944 & 629 \\
\hline R-Anterior-circular-S-insula & 0.04419833 & 4012 \\
\hline R-Inferior-circular-S-insula & -0.0820806 & 1159 \\
\hline R-Superior-circular-S-insula & -0.1217987 & 523 \\
\hline R-Anterior-transverse-collateral-S & -0.1085695 & 660 \\
\hline
\end{tabular}




\begin{tabular}{|c|c|c|}
\hline R-Posterior-transverse-collateral-S & -0.1379085 & 407 \\
\hline R-Inferior-frontal-S & 0.00657545 & 181527 \\
\hline R-Middle-frontal-S & -0.0997017 & 784 \\
\hline R-Superior-frontal-S & -0.0829986 & 1133 \\
\hline R-S-intermedius-primus & -0.0242404 & 13352 \\
\hline R-Intraparietal-S\&transverse-parietal-S & -0.1109044 & 632 \\
\hline R-Middle-occipital-S\&lunatus-S & -0.1580173 & 308 \\
\hline R-Superior-occipital-S\&transverse-occipital-S & -0.0236655 & 14009 \\
\hline R-Anterior-occipital-S\&preoccipital-notch & -0.0035028 & 639706 \\
\hline R-Lateral-occipitotemporal-S & -0.0317386 & 7786 \\
\hline R-Medial-occipitotemporal-S\&lingual-S & -0.1417571 & 385 \\
\hline R-Lateral-orbital-S & 0.04932258 & 3220 \\
\hline R-Medial-orbital-S & -0.0138083 & 41159 \\
\hline R-Orbital-S & -0.1452631 & 366 \\
\hline R-Parieto-occipital-S & -0.0881139 & 1005 \\
\hline R-Pericallosal-S & 0.01345474 & 43351 \\
\hline R-Postcentral-S & -0.0719338 & 1511 \\
\hline R-Inferior-precentral-S & -0.1217513 & 524 \\
\hline R-Superior-precentral-S & 0.12734155 & 478 \\
\hline R-Suborbital-S & 0.08156378 & 1174 \\
\hline R-Subparietal-S & 0.01929028 & 21087 \\
\hline R-Inferior-temporal-S & 0.04123692 & 4610 \\
\hline R-Superior-temporal-S & 4.10E-05 & 4675478286 \\
\hline R-Transverse-temporal-S & -0.0764489 & 1337 \\
\hline \multicolumn{3}{|c|}{ Subcortical GMV } \\
\hline L-Cerebellum-Cortex & -0.0587125 & 2271 \\
\hline L-Thalamus-Proper & -0.1296967 & 461 \\
\hline L-Caudate & 0.15014569 & 342 \\
\hline L-Putamen & -0.0104299 & 72146 \\
\hline L-Pallidum & 0.04398183 & 4052 \\
\hline Brain-Stem & -0.0536815 & 2718 \\
\hline L-Hippocampus & -0.071467 & 1531 \\
\hline L-Amygdala & 0.12002447 & 539 \\
\hline L-Accumbens-area & 0.22622697 & 147 \\
\hline R-Cerebellum-Cortex & -0.1034844 & 727 \\
\hline R-Thalamus-Proper & -0.1606671 & 298 \\
\hline R-Caudate & 0.17319617 & 256 \\
\hline R-Putamen & -0.0491374 & 3245 \\
\hline R-Pallidum & 0.111796 & 622 \\
\hline
\end{tabular}




\begin{tabular}{|l|c|c|}
\hline R-Hippocampus & 0.03552365 & 6214 \\
\hline R-Amygdala & 0.09236651 & 914 \\
\hline R-Accumbens-area & -0.0557185 & 2522 \\
\hline
\end{tabular}

\section{Data statement}

3 All data are available at https://osf.io/zumwt/?view_only=4f11ca10ed5947c1be1ecdea57cfdff3.

\section{Acknowledgements}

5 We thank Tim Armstrong for helping with data collection, and Dorit Kliemann and Julien

6 Dubois for helpful discussion. Funding: This work was supported by a Silvio O. Conte Center

7 from the National Institute of Mental Health (2P50MH094258).

\section{Author contributions}

9 CL carried out preregistration, most data processing except for aspects of the MRI data, and

10 drafted the paper; CL and UK performed all data analysis; JMT carried out MRI data collection,

11 MRI data processing, helped with data analysis, and helped drafting parts of the Methods; MG

12 helped with assembling data, preregistration, and carring out a literature review for the

13 introduction and discussion sections of the paper; LP expanded the Social Network Index to

14 assess modes of communication and types of social support, supervised behavioral data

15 collection, and helped with processing of behavioral data; RA initially conceived of project and

16 helped draft the paper; All authors contributed to intellectual discussions on the project, and all

17 authors participated in revisions to finalize the manuscript. 


\section{References}

2 Asendorpf, J. B., \& Wilpers, S. (1998). Personality effects on social relationships. Journal of Personality and Social Psychology, 74(6), 1531-1544. https://doi.org/10.1037/00223514.74.6.1531

Baron-Cohen, S., \& Wheelwright, S. (2004). The Empathy Quotient: An Investigation of Adults with Asperger Syndrome or High Functioning Autism, and Normal Sex Differences. Journal of Autism and Developmental Disorders, 34(2), 163-175.

Barton, R. A. (1999). The evolutionary ecology of the primate brain. In Comparative primate socioecology (pp. 167-194).

11 Beck, A. T., Steer, R. A., \& Brown, G. K. (1996). Manual for the beck depression inventory-II. San Antonio, TX: Psychological Corporation.

13 Bickart, K. C., Hollenbeck, M. C., Barrett, L. F., \& Dickerson, B. C. (2012). Intrinsic AmygdalaCortical Functional Connectivity Predicts Social Network Size in Humans. Journal of Neuroscience, 32(42), 14729-14741. https://doi.org/10.1523/JNEUROSCI.1599-12.2012

16 Bickart, Kevin C., Wright, C. I., Dautoff, R. J., Dickerson, B. C., \& Barrett, L. F. (2011). Amygdala Volume and Social Network Size in Humans. Nature Neuroscience, 14(2), 163-164. https://doi.org/10.1038/nn.2724 Factor Questionnaire (16PF). Institute for Personality and Ability Testing. 
1 Cohen, S., Doyle, W. J., Skoner, D. P., Rabin, B. S., \& Gwaltney, J. M. (1997). Social Ties and Susceptibility to the Common Cold. JAMA, 277(24), 1940-1944. https://doi.org/10.1001/jama.1997.03540480040036

4 Cohen, S., Kamarck, T., \& Mermelstein, R. (1983). A global measure of perceived stress. Journal of Health and Social Behavior, 385-396.

6 Destrieux, C., Fischl, B., Dale, A., \& Halgren, E. (2010). Automatic parcellation of human cortical gyri and sulci using standard anatomical nomenclature. NeuroImage, 53(1), 1-15. https://doi.org/10.1016/j.neuroimage.2010.06.010

Dunbar, R. I. M. (1998). The social brain hypothesis. Evolutionary Anthropology, 6(5), 178-190.

Dunbar, R. I. M., \& Shultz, S. (2007). Understanding primate brain evolution. Philosophical Transactions of the Royal Society B: Biological Sciences, 362(1480), 649-658. https://doi.org/10.1098/rstb.2006.2001

Dunbar, R. I. M., \& Shultz, S. (2017). Why are there so many explanations for primate brain evolution? Philosophical Transactions of the Royal Society B: Biological Sciences, 372(1727), 20160244. https://doi.org/10.1098/rstb.2016.0244

Dziura, S. L., \& Thompson, J. C. (2014). Social-Network Complexity in Humans Is Associated With the Neural Response to Social Information. Psychological Science, 25(11), 2095-

Finn, E. S., Shen, X., Scheinost, D., Rosenberg, M. D., Huang, J., Chun, M. M., ... Constable, R. 2101. https://doi.org/10.1177/0956797614549209 
of brain connectivity. Nature Neuroscience, 18(11), 1664-1671. https://doi.org/10.1038/nn.4135

Fischl, B. (2012). FreeSurfer. NeuroImage, 62(2), 774-781. https://doi.org/10.1016/j.neuroimage.2012.01.021

Fischl, B., Salat, D. H., Busa, E., Albert, M., Dieterich, M., Haselgrove, C., ... Dale, A. M. (2002). Whole Brain Segmentation: Automated Labeling of Neuroanatomical Structures in the Human Brain. Neuron, 33(3), 341-355. https://doi.org/10.1016/S08966273(02)00569-X

Hampton, W. H., Unger, A., Von Der Heide, R. J., \& Olson, I. R. (2016). Neural connections foster social connections: A diffusion-weighted imaging study of social networks. Social Cognitive and Affective Neuroscience, 11(5), 721-727. https://doi.org/10.1093/scan/nsv153

Haufe, S., Meinecke, F., Görgen, K., Dähne, S., Haynes, J.-D., Blankertz, B., \& Bießmann, F. (2014). On the interpretation of weight vectors of linear models in multivariate neuroimaging. NeuroImage, 87, 96-110. https://doi.org/10.1016/j.neuroimage.2013.10.067

Kanai, R., Bahrami, B., Roylance, R., \& Rees, G. (2012). Online social network size is reflected in human brain structure. Proceedings of the Royal Society B: Biological Sciences, 279(1732), 1327-1334. https://doi.org/10.1098/rspb.2011.1959

Kriegeskorte, N., \& Douglas, P. K. (2019). Interpreting encoding and decoding models. Current Opinion in Neurobiology, 55, 167-179. https://doi.org/10.1016/j.conb.2019.04.002 
1 Kwak, S., Joo, W., Youm, Y., \& Chey, J. (2018). Social brain volume is associated with indegree social network size among older adults. Proc. R. Soc. B, 285. http://dx.doi.org/10.1098/rspb.2017.2708

Lewis, P. A., Rezaie, R., Brown, R., Roberts, N., \& Dunbar, R. I. M. (2011). Ventromedial prefrontal volume predicts understanding of others and social network size | Elsevier Enhanced Reader. NeuroImage, 57, 1624-1629. https://doi.org/10.1016/j.neuroimage.2011.05.030

Mayer, J., Salovey, P., \& Caruso, D. (2002). Mayer-Salovey-Caruso Emotional Intelligence Test Manual. Toronto, CA: Multi-Health Systems.

Nabi, R. L., Prestin, A., \& So, J. (2013). Facebook Friends with (Health) Benefits? Exploring Social Network Site Use and Perceptions of Social Support, Stress, and Well-Being. CyberPsychology, Behavior \& Social Networking, 16(10), 721-727.

14 Noonan, M. P., Mars, R. B., Sallet, J., Dunbar, R. I. M., \& Fellows, L. K. (2018). The structural and functional brain networks that support human social networks. Behavioural Brain Research, 355, 12-23. https://doi.org/10.1016/j.bbr.2018.02.019 revolution. Proceedings of the National Academy of Sciences, 115(11), 2600-2606. https://doi.org/10.1073/pnas.1708274114 
1 Pillemer, S., Holtzer, R., \& Blumen, H. M. (2017). Functional connectivity associated with social networks in older adults: A resting-state fMRI study. Social Neuroscience, 12(3), 242-252. https://doi.org/10.1080/17470919.2016.1176599

Powell Joanne, Lewis Penelope A., Roberts Neil, García-Fiñana Marta, \& Dunbar R. I. M. (2012). Orbital prefrontal cortex volume predicts social network size: An imaging study of individual differences in humans. Proceedings of the Royal Society B: Biological Sciences, 279(1736), 2157-2162. https://doi.org/10.1098/rspb.2011.2574 fifth edition administrator's manual: With updated norms. (3rd ed.). Champaign, Ill:

11 Sallet, J., Mars, R. B., Noonan, M. P., Andersson, J. L., O’Reilly, J. X., Jbabdi, S., ... Rushworth, M. F. S. (2011). Social Network Size Affects Neural Circuits in Macaques. Science,

14 Spagna, A., Dufford, A. J., Wu, Q., Wu, T., Zheng, W., Coons, E. E., ... Fan, J. (2018). Gray matter volume of the anterior insular cortex and social networking. Journal of Comparative Neurology, 526(7), 1183-1194. https://doi.org/10.1002/cne.24402

17 Speilberger, C. D., Gorusch, R. L., Lushene, R., Vagg, P. R., \& Jacobs, G. A. (1983). Manual for the State-Trait Anxiety Inventory. Palo Alto, CA: Consulting Psychologists Press, Inc. by brain structure and function in the amygdala and paralimbic regions. Social Cognitive and Affective Neuroscience, 9(12), 1962-1972. 
bioRxiv preprint first posted online Dec. 27, 2019; doi: http://dx.doi.org/10.1101/2019.12.19.883173. The copyright holder for this preprint (which was not peer-reviewed) is the author/funder, who has granted bioRxiv a license to display the preprint in perpetuity. It is made available under a CC-BY-NC-ND 4.0 International license.

1 Watson, D., Clark, L. A., \& Carey, G. (1988). Positive and negative affectivity and their relation to anxiety and depressive disorders. Journal of Abnormal Psychology, 346353.

3 Wechsler, D. (2011). WASI-II: Wechsler abbreviated scale of intelligence. Antonio, TX: The Psychological Corporation. 